\title{
Labour Productivity Differences \\ Between Domestic and Foreign-Controlled Establishments in the Canadian Manufacturing Sector
}

\author{
by \\ John R. Baldwin* \\ and \\ Naginder Dhaliwal** \\ No. 118 \\ 11F0019MPE No. 118 \\ ISSN: 1200-5223 \\ ISBN: 0-660-18077-4 \\ * Statistics Canada \\ Micro-Economic Analysis Division \\ Ottawa, K1A 0T6 \\ (613) 951-8588 \\ Facsimile Number: (613) 951-5403 \\ Email: baldjoh@statcan.ca \\ ** Agriculture and Agri-Food Canada \\ Industry, Performance and Analysis Directorate \\ Policy Branch \\ Ottawa, K1V 0C6 \\ (613) $759-1745$ \\ Email: dhaliwn@em.agr.ca \\ 【
}

March 1, 2000

This paper was prepared for the National Conference on Policy Research: Creating Linkages: Ottawa, October 1-2, 1998.

The authors' names are listed alphabetically.

This paper represents the views of the authors and does not necessarily reflect the opinions of either Statistics Canada or of Agriculture and Agri-Food Canada. 



\section{Table of Contents}

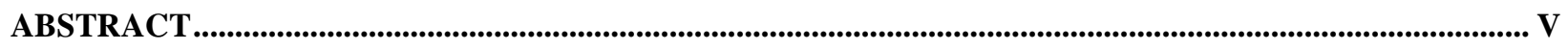

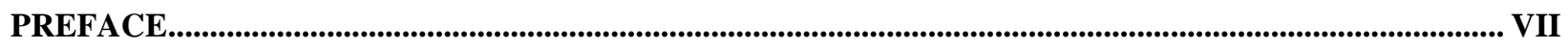

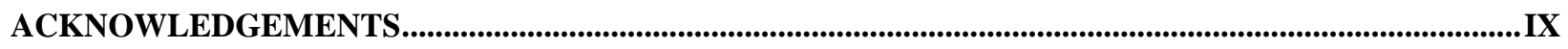

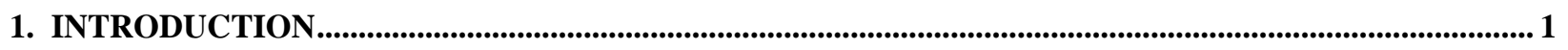

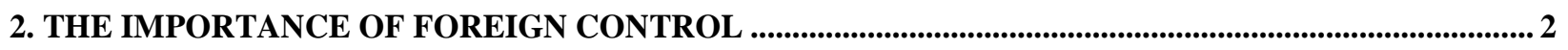

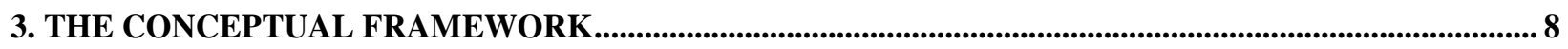

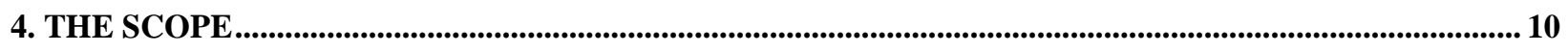

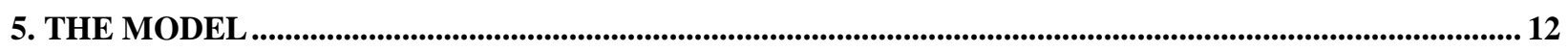

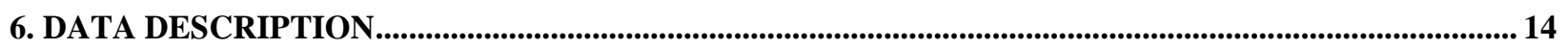

7. MEAN VALUES OF JOB AND OUTPUT CHANGES ................................................................................... 15

8. REGRESSION RESULTS ...................................................................................................................................................... 17

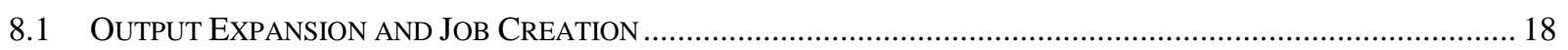

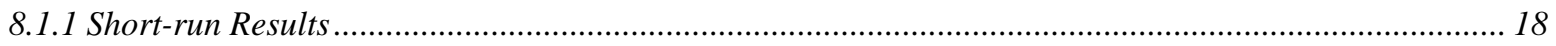

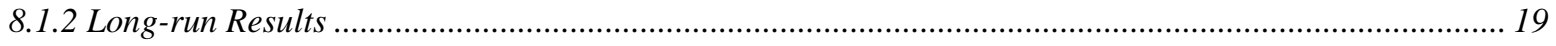

82 OUTPUT CONTRACTION AND JOB DESTRUCTION

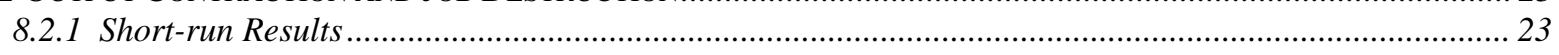

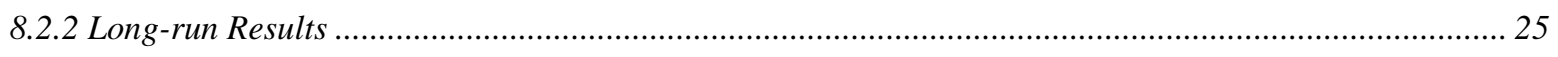

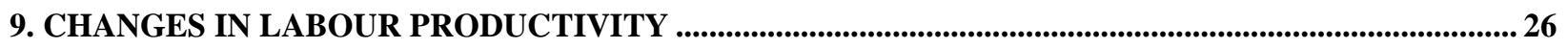

9.1 MeAn VALUES Of AVERAGE Productivity GaINS (LOSSES) .................................................................... 27

9.2 TRENDS IN THE IMPACT OF SizE AND CONTROL ON AVERAGE LABOUR PRODUCTIVITY GrowTH..................... 30

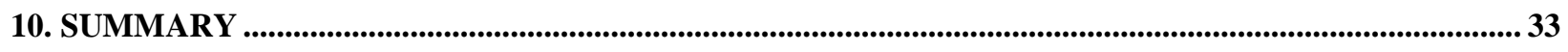

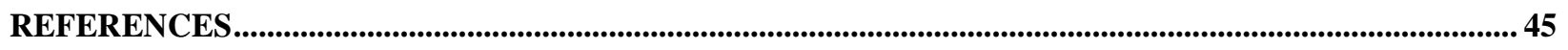





\section{Abstract}

This study uses data to study differences in the growth of labour productivity across domestic and foreign-controlled establishments in the manufacturing sector for the period 1973 to 1993 . In doing so, it also examines the extent to which differences in the growth of labour productivity exist between small and large establishments and across industry sectors and how they have been changing over time.

The analysis consists of four parts. The first section examines differences in average labour productivity between foreign-controlled and domestically controlled plants over the period 19731993. In the second section, the connection between labour usage and output is examined. This analysis investigates differences in how employment responds to output change (marginal labour propensities) for the different subgroups in the short and long-run. Here volatility is shown to be lower for foreign-controlled establishments. The third section examines the difference between the growth in average labour productivity for the same groups. Here foreign-controlled establishments are seen to have the highest growth rates. The fourth section investigates whether any trend can be found in the rates of growth for large and small, domestic and foreign establishments and finds that differences between large and small plants and between foreigncontrolled and domestic plants have been increasing over time.

Keywords: labour productivity, domestic and foreign establishments 


\section{Preface}

The government of Canada has released an Aide Memoir titled "A New Strategy to Attract and Retain International Business Investment" in 1996. The basic tenet of this strategy is that capital investment is important for economic growth and development of the Canadian economy. Agriculture and Agri-Food Canada (AAFC) is a major partner in this initiative.

As part of this initiative, the Policy Branch of AAFC undertook to carry out economic research to improve our understanding of the impact of foreign direct investment (FDI) on output growth, trade and employment. This paper was undertaken jointly by the Policy Branch and the MicroEconomic Analysis Division of Statistics Canada, and studies the affects of FDI on the level of employment and labour productivity in the food and beverage sector in relation to other manufacturing sectors of the Canadian economy. 


\section{Acknowledgements}

The authors wish to thank Don Trefler of the University of Toronto and Richard Caves of Harvard for their comments. Richard Vincent of Statistics Canada also provided valuable comments. All remaining errors are our responsibility. 


\section{Introduction}

Economic objectives are multidimensional-involving both rates of increase in productivity (a measure of the capacity of the economy to produce more per worker) and the provision of jobs. Recently, high unemployment in Canada, relative to the United States has led to concerns about the capacity of the economy to provide new jobs. As well, the productivity growth in the Canadian manufacturing sector relative to that in the United States has increasingly become a concern.

This study examines two associated aspects of performance-the response of job-change to output change (marginal labour productivity) and the growth in average labour productivity (output per worker). Job change measures the employment change that occurs as plants expand or contract. The growth in labour productivity captures the relationship between the rate of change in jobs and the rate of change in output. Marginal productivity gains of labour are higher when a given increase in output is accommodated with a smaller increase in labour input. In contracting establishments, labour productivity gains are larger where, for a given contraction in output, the decline in labour output is relatively large. The growth in labour productivity is larger where the rate of growth of output minus the rate of growth of labour is higher.

Discussions of productivity and job growth usually focus on economy-wide aggregates. The course of these aggregate measures is determined by the performance of sub-populations that differ in terms of such characteristics as plant size or nationality of control. In this study, we examine differences in marginal labour productivity and the growth of labour productivity across plant size classes and between domestic- and foreign-controlled plants.

An examination of differences across size classes is important since Baldwin and Picot (1995) note that job growth in the manufacturing sector has been predominantly concentrated in small establishments; but labour productivity is lower in small establishments and falling relative to large establishments (Baldwin, 1998). The growth in the share of employment in small establishments could, therefore, have had the effect of slowing productivity growth in the manufacturing sector (Baldwin, 1996).

An examination of differences in productivity growth by nationality is equally important since foreign-controlled firms are mostly large and capital intensive and are often seen as the vehicle through which new technologies are incorporated most quickly into the economy. These firms account for about 55 percent of shipments in the manufacturing sector as of 1993 and, therefore, have an important impact on both aggregate productivity and job growth.

Marginal labour productivity differences between foreign- and domestic-controlled plants and between large and small plants will be manifested by differences in the extent to which changes in plant's employment are associated with changes in its output. Therefore, this paper first examines the extent to which the domestic and foreign-controlled segments, as well as the large and small segments of the manufacturing sector, differ in adjusting labour input in response to output changes or how marginal labour productivity differs across these groups. In the second section, we ask how differences in marginal labour productivity are reflected in differences in the 
growth of average labour productivity across plant size classes and broad industry sectors. Differences in these productivity relationships reflect differences in technology, capital intensity, size, and other firm-specific factors. This paper does not examine which of these has caused differences in labour productivity between foreign and domestic plants. It focuses only on the magnitude of these differences.

\section{The Importance of Foreign Control}

Over the past twenty years, the policy regime that affects foreign investment has changed dramatically in two ways. First, trade liberalization has seen tariffs gradually reduced over time. The Kennedy round of GATT tariff reductions was felt in the 1970s. The Tokyo round followed in the 1980s. These two multilateral rounds of tariff reductions were followed by the bilateral reductions between Canada and the United States as a result of the Canada-US free trade agreement (FTA) in 1989 and then the North American Free Trade Agreement of 1994 (NAFTA).

While tariff reductions reduced the barriers to the movement of goods, changes in the investment regulatory regime have reduced barriers to the movement of capital. Prior to 1983, the Foreign Investment Review Agency regulated foreign investment. In 1983, this was replaced with a new agency (Investment Canada), whose mandate was seen to be less restrictive-as facilitating and soliciting foreign investment rather than controlling it. At the same time, foreign investment provisions of both FTA and NAFTA changed the thresholds required for review before the agency.

Liberalized trade regulatory regimes might be expected to affect foreign direct investment in a number of ways. First, reductions in regulation reduce the cost and uncertainty involved with foreign investment and should be expected to increase investment. Second, tariff reductions allow firms greater flexibility in optimizing their production facilities. Whether this would result in foreign operations leaving Canada depends on whether the Canadian market can be better served from abroad or with production facilities in Canada once tariffs are decreased and whether Canada has a comparative advantage in some areas that would lead production to be located here.

Traditional theories of foreign trade try to answer this question by focusing on the extent to which country-specific factors that determine the costs of business affect the pattern of international trade. The costs of business are determined by factor endowments, the height of transportation costs, tax and regulatory regimes, and exchange rate stability. These comparative advantage theories are not ideally suited to explain the creation of multinational firms-an organization that has production facilities in different countries. In response, a theory of a transnational firm has been developed to explain why firms internalize transactions across national boundaries rather than engaging in arm's-length trade.

One strand of this literature focuses on the existence of assets that are difficult to trade-either because these knowledge-based assets lead to asymmetric information difficulties or problems in writing contracts, evaluating results and monitoring performance. These assets could involve 
proprietary production technology, unique marketing skills, trademarks, or brand names (Caves, 1982). Because assets are assumed to be difficult to exchange efficiently via market mechanisms, firms are seen to set up shop abroad rather than sell or license rights for use of their assets by local firms in foreign markets.

In this vein, Dunning (1993) argues that an MNE (Multinational Enterprise) will develop if there are compelling reasons for a firm to internalize economic activity rather than to rely on markets. These could be related to the difficulty of exchanging company-specific assets through the marketplace. Alternately, there may be efficiency reasons for undertaking foreign direct investment (FDI). Just as a single-nation firm internalizes some economic activity for reasons of efficiency (e.g., keeping a pay division on staff rather than contracting out payroll services), so too an MNE may obtain efficiency gains by bringing together various internationally dispersed entities under common ownership. In still other cases, the opportunity to ensure a steady supply of inputs, or a guaranteed market for outputs through vertical integration may be a compelling reason to internalize arm's-length transactions.

Adopting this framework, we can adduce several reasons that foreign investment in Canada may have changed over the last twenty years. First, regulatory policy changes may have changed the profitability of foreign direct investment. Second, the reduction in tariffs may have influenced the relative cost of doing business in Canada and changed the incentive to internalize production.

Of course, changes in several other fundamentals may also have affected foreign investment in Canada. First, outsourcing has increased in some industries-particularly in industries selling branded products where firms have learned that they can reduce costs by contracting out their manufacturing operations. This is evidence of a reduction in the benefits of internalization and a reduction in the benefits of internalization should result in a reduction of transnational investment. Second, the stability of developing markets has increased over the last thirty years and, therefore, the relative advantage of Canada as a secure source of raw materials over production facilities in developing markets has decreased. In turn, multinational investment in some sectors could have shifted away from Canada. Third, the importance of knowledge assets may have increased as the result of the type of technological progress taking place. As new advanced computer-based technologies have been incorporated into the production process, knowledge assets are seen by some to have become more important. ${ }^{1}$ This, in turn, would have increased the benefits from and the extent of internalization and the amount of multinational investment in Canada.

In order to assess how these and other changes have affected the role played by foreigncontrolled firms in Canada, we first investigate how their share of Canadian manufacturing sector output has changed over time. Their market shares are derived from establishment data, taken from the Census of Manufactures, which classifies each plant by ownership typedomestically or foreign-controlled. The changes in the importance of foreign-controlled firms in the Canadian manufacturing sector over the period from 1973 to 1993 are measured using both

\footnotetext{
${ }^{1}$ Baldwin, Gray and Johnson (1996b) show that training is much more intense in firms that are adopting the new computer-based technologies.

${ }^{2}$ These data provide a finer level of industry detail that is provided by classifications that use firm-based data, such as are provided by Corporations and Labour Unions Returns Act (CALURA).
} 
shipments and value-added (Figure 1). We also report their share of labour inputs-defined as the sum of production and non-production workers.

Prior to the 1980s, the share of output in manufacturing accounted for by foreign-controlled firms declined to reach a low in 1981 and 1982. Subsequently, there was a steady increase in output share. While the foreign share of output has increased, its share of employment has decreased continuously over time. The relative labour productivity (defined in terms of output per worker and measure using both shipments per worker and value added per worker) has, therefore, increased (see Figure 2). Except for the two recession-related downturns, the increase has been more or less steady over the entire time period. An increase in the relative wage per worker paid by foreign-controlled plants has accompanied this increase in relative labour productivity.

Thus, the foreign-controlled sector has been holding its own with respect to output share but its employment share has been steady or declining. As a result, labour productivity has been increasing more rapidly in the foreign than the domestic sector.

The aggregate data that are presented in Figures 1 and 2 may hide a great deal. In particular, the performance of foreign firms may vary across sectors. Figures 3 and 4 examine changes in foreign ownership and relative productivity across six sectors-food and beverages, natural resources, labour intensive, scale-based, product differentiated and science-based industries. The five groups are defined on the basis of the primary factors affecting the competitive process in each sector. For the resource-based sector, the primary factor affecting competition is access to abundant natural resources. For the labour-intensive sector, it is labour costs. For scale-based industries, it is the length of production runs. For differentiated goods, it is tailoring production to highly varied demand conditions. For science-based industries, it is the rapid application of scientific advance.

A very similar pattern is found for changes in market shares in most sectors - with an initial decline followed by an increase in the 1990s. The relative labour productivity of foreign-owned establishments increases over time in most sectors.

The differences between the productivity of foreign and domestic plants can originate from different sources-different technologies, more capital, different plant sizes, and variations in industry of location. Here we consider whether size and industry differences serve to explain much of the differences in relative productivity and changes therein. ${ }^{4}$ Foreign plants are larger than domestic plants and larger plants are generally more capital intensive and, therefore, have a higher labour productivity. Foreign plants are also more concentrated in certain sectors (scalebased) than are domestic plants (see Figure 3) and the latter two sectors are among the more capital intensive (Baldwin and Rafiquzzaman, 1994).

\footnotetext{
${ }^{3}$ For a discussion of the definitions of these sectors, see Baldwin and Rafiquzzaman, 1994.

${ }^{4}$ Globerman, Ries and Vertinsky (1994) use micro data for a limited number of industries to argue that most of the differences relate to size and capital intensity, the latter being proxied by energy use.
} 
Figure 1

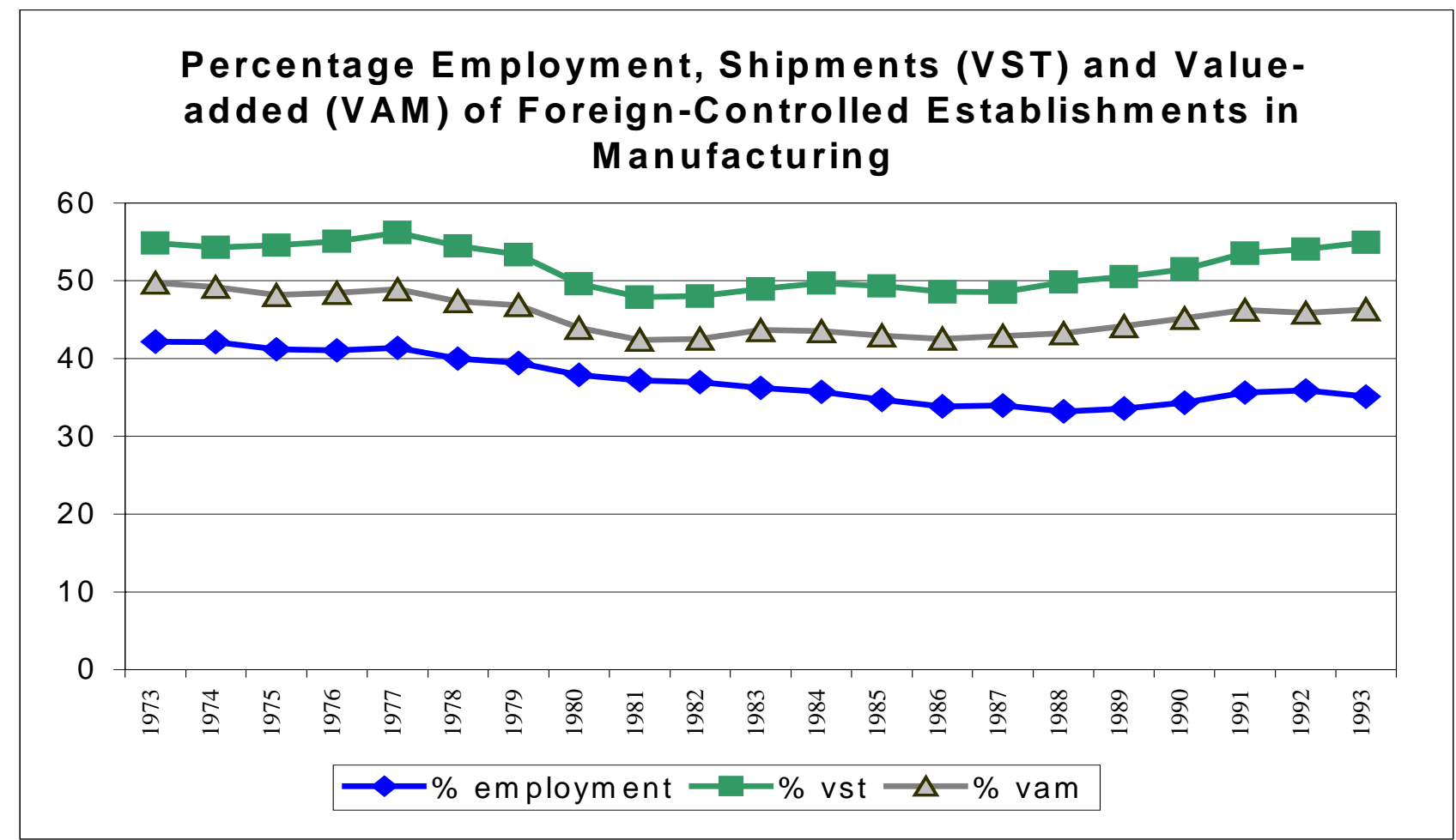

Figure 2

\section{Relative Remuneration (REM) and Shipments (VST) per Employee (EMP)-Foreign Divided by Domestic Establishments}

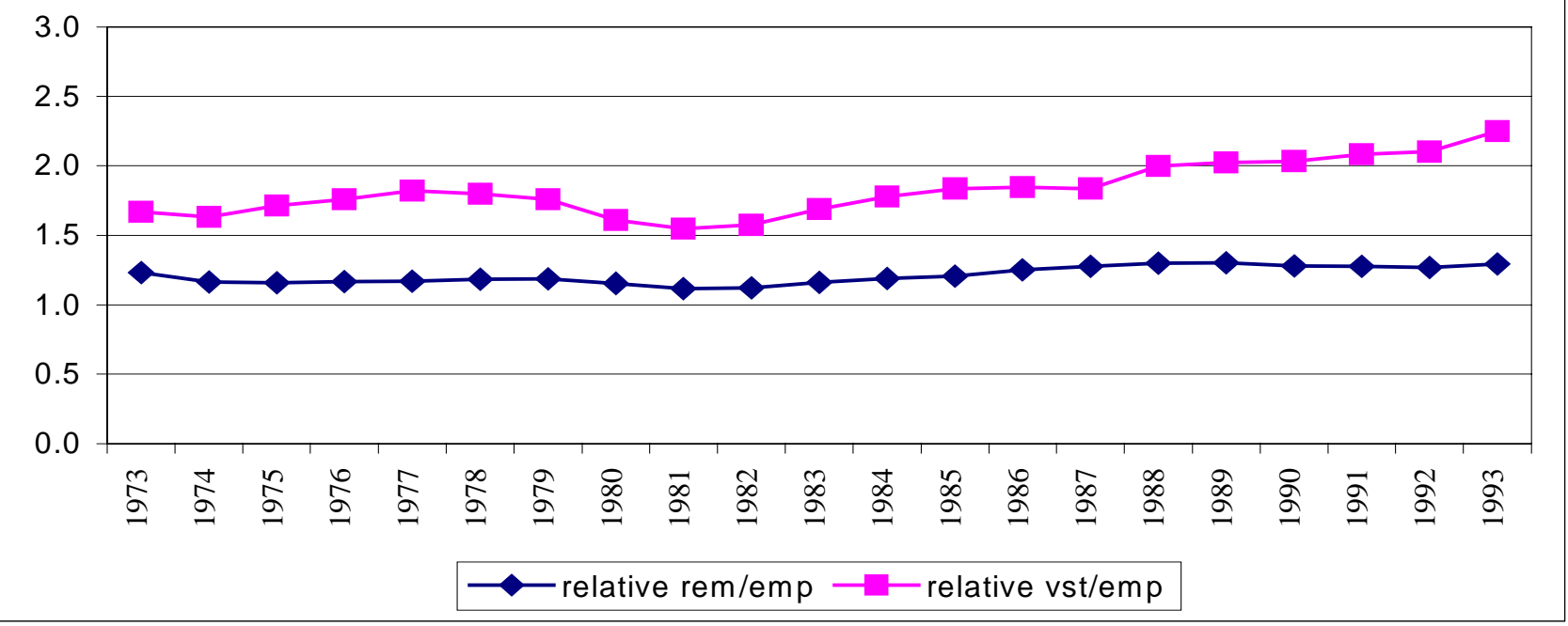


Figure 3

\section{Foreign-controlled Market $S$ hare by Sector}

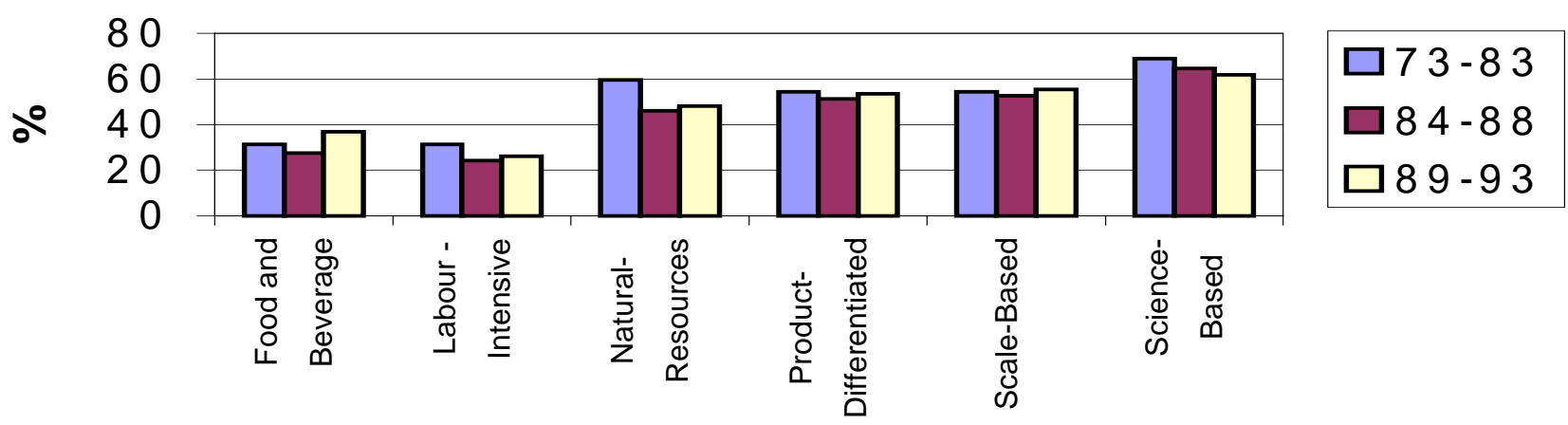

Figure 4

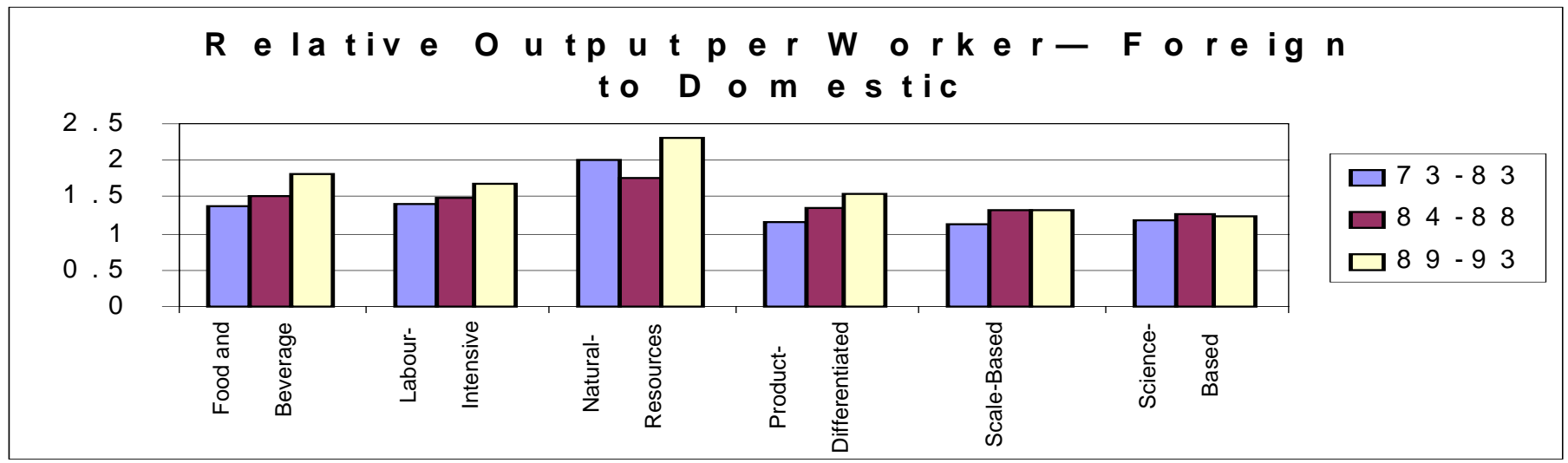


Both of these factors would make the labour productivity of foreign plants higher than domestic plants. We can determine how much of the total difference between the two groups is the result of differences in composition by comparing the coefficients on foreign control using the following regressions:

(1) $\log ($ Labour productivity $)=\alpha+\beta$ ( Foreign control)

(2) $\log ($ Labour productivity $)=\alpha+\delta($ Foreign control $)+\gamma($ Size $)+\eta$ (Industry)

In these equations, FOREIGN control is a binary variable taking on a value of 0 if domestically controlled and 1 if foreign controlled; Size consists of three binary variables for the three groups used in this paper-0 to 100 employees, 101 to 250 employees, and $250+$ employees; and Industry consists of five binary variables for the following sectors-labour intensive, naturalresources, product-differentiated, scale-based, and science-based.

In order to test whether the choice of output measure matters, we employ both shipments per worker and value added per worker as measures of labour productivity and perform regressions 1 and 2 on micro-data derived from the Census of Manufactures using ordinary least squares (OLS).

The ratio of foreign to domestic value added when no account is taken of size class or indystry (equation 1) is provided by the coefficient attached to foreign control in equation (1) ${ }^{6}$ and reported in columns 2 and 5 of Table 1 for the years 1973, 1983, 1989, and 1993. The ratio of foreign to domestic value added when account is taken of size class and industry differences (equation 2) is provided by the coefficient attached to foreign control in equation (2) and reported in columns 3 and 6 of Table 1.

Table 1. The Ratio of the Labour Productivity of Foreign to Domestic Plants-Effect of Controlling for Size and Industry Differences

\begin{tabular}{c|r|r|r|r|r|r}
\hline & \multicolumn{3}{|c|}{ Shipments Per Worker } & \multicolumn{3}{c}{ Value Added per worker } \\
\hline Year & No Control & $\begin{array}{c}\text { Control for } \\
\text { Size and } \\
\text { Industry }\end{array}$ & Difference & No Control & $\begin{array}{c}\text { Control for } \\
\text { Size and } \\
\text { Industry }\end{array}$ & Difference \\
\hline$(1)$ & $(2)$ & $(3)$ & $(4)$ & $(5)$ & $(6)$ & $(7)$ \\
\hline 1973 & 1.80 & 1.73 & 0.07 & 1.66 & 1.57 & 0.09 \\
1983 & 2.09 & 1.90 & 0.19 & 1.92 & 1.73 & 0.19 \\
1989 & 2.22 & 1.96 & 0.26 & 2.12 & 1.86 & 0.26 \\
1993 & 2.27 & 1.96 & 0.30 & 2.07 & 1.80 & 0.26 \\
\hline
\end{tabular}

Comparing the results with and without allowance for differences in size and industry reveals that size and industry account for some of the difference between foreign and domestic plants. In 1973, shipments per worker in foreign plants were $80 \%$ higher than in domestic plants when no account is taken of size and industry differences and $73 \%$ after. The comparable figures for value added per worker were $66 \%$ and $57 \%$.

\footnotetext{
${ }^{5}$ For this purpose, we use all production establishments.

${ }^{6}$ The value of the ratio of the labour productivity of foreign to domestic plants is given by exp $(\beta)$.
} 
In figure 2, we demonstrated that output per worker in foreign plants as a group went up relative to domestic plants using the weighted average output per worker of foreign relative to domestic plants. Those results are similar though not identical to the unweighted OLS results presented in column 2, Table 1 that use individual micro data that do not allow for industry and size differentials. The latter show an increase of overall foreign productivity from a level in 1973 that is $80 \%$ higher than domestic labour productivity to a level in 1993 that is $127 \%$ higher. When account is taken of size and industry composition, there still is an increase in the relative productivity of foreign controlled plants. After size and industry controls are used, shipments per worker in foreign plants increase from a level $73 \%$ higher than domestic plants to $96 \%$ higher. Using value added per worker, the increase is from $57 \%$ to $80 \%$ (column 6 , Table 1 ).

Part of the changes in the productivity differences between the two groups arise from changes in the composition of domestic and foreign plants by size and industry. The amount that is attributed to compositional effects is found in columns 4 and 7-the difference between the results without controls for plant size and industry and with controls for these factors. It is apparent that this difference widens over time. Between $40 \%$ and $50 \%$ of the increase in the overall difference between foreign and domestic (columns 2 and 5) stems from this compositional shift.

These data then show that the overall differences between foreign-controlled and domestically controlled plants are not just the result of compositional shifts. It nevertheless might be the case that differences between the two groups occur disproportionately within specific subpopulations. In the following sections, we examine the differences in marginal labour productivity. We then turn to how these differences in marginal labour productivity translate into differences in the growth rates of labour productivity across different size classes and different industries.

\section{The Conceptual Framework}

Productivity growth is not spread evenly across all establishments. In any population of establishments, some will be increasing productivity, others will be falling behind. When those establishments that are expanding their productivity are also increasing their relative importance because they are growing in relative size, this process of expansion will contribute to productivity growth (Baldwin, 1995).

Previous work has examined the proportion of productivity growth that can be attributed to different groups of establishments — entrants (Baldwin and Gorecki, 1991) —or to market share being shifted from one incumbent to another (Baldwin, 1995, 1996). In these previous studies, incumbents were divided into those gaining and those losing market share. Here, we divide the population into two quite different groups of establishments-initially, into those where jobs are being created and those where jobs are being eliminated. ${ }^{\square}$ This choice is determined by the intrinsic interest in each. Job creation is generally regarded favourably; job contraction unfavourably.

\footnotetext{
${ }^{7}$ Bailey, Bartelsman and Haltiwanger (1996) also use this distinction.
} 
As attractive as this classification may be, care must be exercised in making inferences from it about who is doing well and who is doing poorly. The job performance of firms is ineluctably connected to both output growth and productivity change. Job change at the establishment level is determined by how the demand for labour varies with output change.

That very connection means that it is difficult to make generalizations about performance using job growth and job contraction categories by themselves.

For example, employment contraction is sometimes seen to be the sign of a failing firm. Yet, a firm that faces a stagnant market and radically changes its technology in order to improve productivity will contract employment - and this type of firm cannot be characterized as a failure. Similarly, a firm that is expanding employment in lock-step with expanding output would be judged to be performing well if only employment is examined; yet its productivity is standing still.

It is often the case that firms in the early stages of their life cycle focus more on product innovation than cost-cutting process innovation and they have to expand inputs dramatically just to keep up with the growth in market demand. Continued growth, as a market matures, requires a firm to move away from pure product innovation to process innovation. At this stage, firms implement productivity improvements that will reduce unit costs. A firm that fails to achieve unit cost reductions via productivity improvements will not survive the transition from the early to the later stages of market development.

At any time, the population is made up of firms, some of which are in the early phases of market development, others which are in the later stages of market development. Some firms will be facing relatively mature markets. These will, if they are adapting successfully to the later stages of the life-cycle, be increasing productivity and reducing unit costs by reducing, inter alia, their requirements for labour per unit of output. Often this is done by increasing capital intensity. Their sales may also have reached a plateau. Other firms will be in their growth phase, when it is all they can do to just keep up with growing demand, where innovative activities focus more on product innovation than on cost-based process innovations. The latter group of firms will probably have less productivity growth because they are still expanding rapidly and have not yet moved to the mature phase of the market where competition is based more on prices than on new-product introduction.

A decline in employment in a firm is, therefore, not necessarily evidence of the decline of the firm; it may be associated with productivity gains during the mature phase of the life cycle. An examination of employment change alone does not allow us to conclude the reasons for employment change. If we are to study employment change and how firms are responding to output change, we must be cognisant of the extent of heterogeneity in the population and the various reasons that a firm may be increasing or decreasing employment. 


\section{The Scope}

To do so, we ask how labour input responds differentially to output changes in different size and nationality groups and how marginal labour productivity differs across these groups. Within each of the expanding and declining groups, the response of labour demand to output change is examined by industry, establishment size and nationality. The latter distinction allows us to test the proposition that productivity growth in the foreign sector was greater than in the domestic sector and to ask when these differences emerged.

The analysis investigates differences in the labour adjustment process over several important dimensions-involving time, size, nationality, and industry.

\section{a) Long Versus Short-run}

First, we recognize that the adjustment mechanism differs between the short and the long-run and, therefore, we estimate both.

Writing desired labour demand as a function of expected output $\left(Q^{\mathrm{E}}\right)$

(3) $\mathrm{L}^{\mathrm{E}}=\mathrm{f}\left(\mathrm{Q}^{\mathrm{E}}\right)=\alpha * \mathrm{Q}^{\mathrm{E}}$ where $\alpha$ depends on the production function and determines the marginal productivity of labour.

Changes in the desired level of labour are:

(4) $\Delta \mathrm{L}^{\mathrm{E}}=\alpha * \Delta \mathrm{Q}^{\mathrm{E}}$

If only part of desired changes in any period are implemented due to adjustment costs, ${ }^{\text {B }}$

(5) $\Delta \mathrm{L}=\beta * \Delta \mathrm{L}^{\mathrm{E}}=\beta * \alpha * \Delta \mathrm{Q}^{\mathrm{E}}$ where $\beta$ is the proportion of the desired change that is implemented. When costs of adjustment are high, $\beta$ will be less than 1 .

Expectations about sales can be written as a function of actual sales changes, that is

(6) $\mathrm{Q}_{\mathrm{t}}^{\mathrm{E}}-\mathrm{Q}_{\mathrm{t}-1}^{\mathrm{E}}=\delta *\left(\mathrm{Q}_{\mathrm{t}}-\mathrm{Q}_{\mathrm{t}-1}\right)=\delta * \Delta \mathrm{Q}$

where $\delta$ is the rate at which expectations are adjusted as sales change.

Then solving equations (4) and (5) gives

(7) $\Delta \mathrm{L}=\beta * \alpha * \delta * \Delta \mathrm{Q}=\eta * \Delta \mathrm{Q}$

The analysis that follows focuses on the differences that exist in the coefficient $\eta$ between small and large establishments as well as growing and declining establishments, in the short- and the long-run. By comparing the estimates of $\eta$ between the short- and the long-run, we can ascertain whether establishments have the same fixities that affect the extent to which they can adjust labour inputs to output fluctuations.

\footnotetext{
${ }^{8}$ See Hamermesh (1993) for a discussion of formal cost minimizing models that yield these adjustment processes.
} 
There are, in this model, several reasons that the short- and the long-run coefficients can differ. In the first instance, the coefficients determining labour productivity $(\alpha)$ should decline in the long-run for growing plants as establishments adjust their production processes to reflect their increased size. Larger establishments tend to be more capital intensive and would be expected to have a lower value of $\alpha$. In contrast, the adjustment coefficient $(\beta)$ should increase in the longrun as labour fixities are overcome. In the short-run, factors such as the extent of labour hoarding, the presence of excess capital capacity, establishments' perceptions of whether the change in output demand is short lived or permanent, imperfections in the labour market (e.g., wage fixity and the inability of supply to adjust quickly to demand), all play prominent roles causing $\beta$ to be less than 1. The long-run, on the other hand, provides establishments with greater flexibility to adjust inputs (i.e., factors can more easily be substituted for one another). As a result, the adjustment coefficient $\beta$ is postulated to approach 1 as the period of adjustment is lengthened. Therefore, the response of labour demand in the long-run to output change is less likely to be determined by inflexibilities associated with treating labour as a fixed cost (since $\beta$ approaches 1) and differentials across firm types should more closely reflect differences in productivity growth $(\alpha)$. Finally, the expectations coefficient $\delta$ also may increase in the long-run. If long-run change is taken to be a better indicator of performance, it could increase. However, if long-run change is simply the cumulation of annual changes and if the latter exhibits no clear trend, the adjustment coefficient may not differ much between the short- and long-run.

\section{b) Size and Nationality Effects}

Second, our analysis focuses on differences in the relationship between job and output change across groups that differ by size and nationality of control. Other studies have pointed to differences in worker separations rates across size classes as evidence of greater volatility in small establishments (Baldwin and Gorecki, 1990; Picot, Lin and Pyper, 1997). Since small establishments have higher exit rates than large establishments (Baldwin and Gorecki, 1990), the higher job volatility in small establishments may not be the result of any inherent differences in the reaction of incumbent establishments to changes in output. It may simply be the result of differences in the volatility of output. By investigating whether small incumbent establishments react differently to output changes, we can directly test the proposition that small-establishment labour markets are more volatile than large-establishment labour markets because of differences in their responses to output changes.

Size is not the only establishment characteristic that may affect the fixities involved in labour adjustment. Foreign establishments are sometimes portrayed as possessing certain asset-specific fixities. Labour skills may partially account for these fixities. We, therefore, also examine whether foreign-controlled establishments demonstrate greater inflexibilities than domesticcontrolled establishments.

\section{c) Industry Effects}

Third, we examine differences in the labour demand function across industries. Establishments that differ by sector, size class and country-of-control may not respond in the same way to output changes because there are interindustry differences in scale economies, the development and adoption of new technologies, the nature of competition, and longer-term business strategies. To 
investigate this, we classify establishments by sector and ask whether employment reactions indicate more short-run inflexibility in industries where the fixed costs of hiring and separation are, a priori, higher.

\section{d) Asymmetric Growth Effects}

Fourth, we postulate that the relationship between labour input and output may be asymmetric between establishments that are growing and those that are downsizing. These differences may exist for both short- and long-run estimates. In the short-run, imperfections that prevent full labour-market adjustments are posited to exist $(\beta<1)$, for both expanding and contracting establishments; but these imperfections are not necessarily the same for the two groups. Adjustment is not instantaneous for growing plants when hiring costs are an increasing function

of the number of new hires; adjustment of labour inputs is not instantaneous for declining establishments if there are fixed costs associated with hiring and, therefore, layoffs are made reluctantly for fear that some workers will find other jobs and require a costly replacement process. In addition, the two groups may differ if expanding and contracting establishments have different views about the extent to which changes in output are permanent.

There are also reasons to expect that the adjustment process will be asymmetric in the longer run since marginal labour productivity is likely to differ for establishments that are growing and declining for reasons associated with the industry life-cycle that were previously outlined.

\section{The Model}

Since labour inputs are postulated to depend on output (i.e., $\mathrm{L}=\mathrm{f}(\mathrm{Q})$ ), changes in labour input are regressed on changes in output.

$$
\Delta \mathrm{L}_{\mathrm{t}}=a+b \Delta \mathrm{Q}_{\mathrm{t}}+\mathrm{e}_{\mathrm{t}}
$$

The coefficient $b$ is a measure of the marginal labour productivity of establishments. Changes in labour are measured, in the first instance, as job growth $(\mathrm{G})$ and, in the second, as job contraction (C). For positive changes in output, the smaller is $b$, the less additional labour is required to produce additional output and the higher is marginal labour productivity. If output change is negative, the larger is $b$, the greater will be the decline in labour requirements.

This relationship is estimated for sets of establishments that are grouped into three size classes and two nationality groups. Taking first differences as is done in equation (3) accounts for fixed effects at the level of establishment size and nationality. 
The relationship depicted in equation (3) was allowed to vary by size and nationality group by using binary variables. These are:

$$
\begin{aligned}
\mathrm{S}_{1} & =1, \text { if the establishment is small (employees less than 100) } \\
& =0, \text { otherwise; } \\
\mathrm{S}_{2} & =1, \text { if the establishment is of medium size (employees between 100-250) } \\
& =0, \text { otherwise } \\
\mathrm{S}_{3} \quad & =1, \text { if the establishment is large (employees more than 250) } \\
& =0, \text { otherwise } \\
\mathrm{CC} \quad & =1, \text { if the establishment is Canadian-controlled } \\
\mathrm{CF} \quad & =1, \text { if the establishment is foreign-controlled } \\
& =0, \text { otherwise; }
\end{aligned}
$$

To account for differences across sub-sectors, equation (3) was estimated separately for each of the constituent sub-groups of the Canadian manufacturing sector described in section 1 . These groups are the food and beverage sector, the natural resource sector excluding food and beverages, the labour-intensive sector, the scale-based sector, the product-differentiated sector, and the science-based sector.

The labour-intensive sector is the least capital intensive. The capital intensity (measured by the capital/labour ratio) of the other sectors (indexed to 100 for the labour intensive sector) is 120 for the science-based sector, 146 for the product-differentiated sector 335 for the natural-resource sector (including agriculture) and 340 for the scale-based sector. ${ }^{10}$ Fixities that determine the reaction of labour demand to short-run changes in output should be associated with greater capital intensity.

In addition to estimating labour-response functions for each sector, we also pooled the data for all manufacturing industries and equation (3) was estimated with a binary variable (FB) to distinguish the food and beverage sub-group from the rest of the manufacturing sector. 11

The estimating equation for each industry sector is:

$$
\begin{aligned}
\Delta \mathrm{L}_{\mathrm{t}}=\mathrm{a} & +\mathrm{S}_{2}+\mathrm{S}_{3}+\mathrm{CF}+\mathrm{b}_{0} \Delta \mathrm{Q}_{\mathrm{t}}+\mathrm{b}_{1} \Delta \mathrm{Qt}^{*} \mathrm{~S} 2 \\
& +\mathrm{b}_{2} \Delta \mathrm{Qt}^{*} \mathrm{~S} 3+\mathrm{b}_{3} \Delta \mathrm{Qt} * \mathrm{CF}
\end{aligned}
$$

And for the pooled data:

$$
\begin{aligned}
\Delta \mathrm{L}_{\mathrm{t}}=\mathrm{a} & +\mathrm{S}_{2}+\mathrm{S}_{3}+\mathrm{FB}+\mathrm{b}_{0} \Delta \mathrm{Q}_{\mathrm{t}} \\
& +\mathrm{b}_{1} \Delta \mathrm{Q}_{\mathrm{t}} * \mathrm{~S}_{2}+\mathrm{b}_{2} \Delta \mathrm{Q}_{\mathrm{t}} * \mathrm{~S}_{3}+\mathrm{b}_{3} \Delta \mathrm{Q}_{\mathrm{t}} * \mathrm{CF} \\
& +\mathrm{b}_{4} \Delta \mathrm{Q}_{\mathrm{t}} * \mathrm{FB}
\end{aligned}
$$

\footnotetext{
${ }^{9}$ See Baldwin and Rafiquzzaman (1994), for a discussion of how these sectors were created from standard industrial classifications (SIC).

${ }^{10}$ Ibid.

11 The individual regressions were estimated with corrections for serial correlation and heteroscedasticity. The overall pooled sample corrected for first-order serial correlation, contemporary correlation between the cross sections and heteroscedasticity.
} 
It should be noted that while the slope coefficients are allowed to vary across plant sizes, these shifts are constrained to be equal for both Canadian- and foreign-controlled establishments.

\section{Data Description}

The data used in this analysis are taken from the micro-economic records on establishments collected by the Canadian Census of Manufactures and cover the period 1973-1993. Focusing on establishment data is advantageous because it allows us to move closer to the product or business line than would be the case if firm-level data were used. Growth and decline that is associated with product life cycles is obfuscated when firm-level data are used because firms are constantly merging and divesting themselves of plant and, therefore, a good portion of firm growth occurs because of these control changes. For this analysis, we want to avoid these effects.

For this study, the records for individual establishments are linked through time, allowing the dynamics of establishments to be investigated. ${ }^{13}$ The establishments are classified by four-digit industries using the Standard Industrial Classification (SIC) system, nationality of control (Canadian versus foreign-controlled) ${ }^{14}$, and size (small, medium, and large). The size codes were assigned each year, allowing establishments to switch from one size category to another as they grow or downsize over time. The four-digit SIC industry codes were grouped into five broad industries - the natural-resource, labour-intensive, scale-based, product-differentiated and science-based sectors. Further, in keeping with the focus of this study, the natural-resource sector was partitioned into two sub-sectors-food and beverages and other natural-resource industries. In all, these classification criteria grouped the manufacturing establishments into 36 categories, i.e., six sectors, three size classes and two types of control (Canadian and foreign).

Within each category, establishments were grouped into those whose employment increased and those whose employment decreased and the employment change as well as the change in shipments were calculated at the level of the 36 categories. 15 For example, one data set consists of job growth and output change for each of these 36 categories for 20 years; the other for job loss and associated output change. Job growth encompasses both employment in entrants and job change in growing continuing establishments. Job contraction consists both of job change due to exits and change in contracting continuing establishments.

Labour productivity is used in this report. Labour productivity will grow because of increases in the inherent efficiency of a firm, but also because of increases in the amounts of other inputs that are combined with labour-in particular the amount of capital that is available per unit of labour.

\footnotetext{
${ }^{12}$ We experimented with alternate assumptions but found that we could not reject the null hypothesis that shifts in the slopes between foreign and domestic firms were the same across size classes.

${ }_{13}^{13}$ Baldwin and Gorecki (1990) provide details on the creation of the data set.

${ }^{14}$ Corporations are assigned a country of control under the Corporations and Labour Unions Returns Act (CALURA) based on the country of residence of the persons having the greatest potential to strategically influence the activities of the corporations.

${ }^{15}$ Grouping was done to reduce the errors in measurement that occur at the level of the individual establishment and to reduce the computational complexity of the regression analysis for this paper.
} 
Change in output is measured in terms of changes in total shipments. ${ }_{16}$ Employment is measured as the total number of workers (administrative or salaried workers plus production workers). Changes in shipments were expressed in real terms (1992 dollars), with the nominal values of each establishment being deflated by the 4-digit output price index for the industry in which the establishment is classified. Alternatives could have been chosen. For example, we could have used value added as defined in the Census of Manufactures. The latter concept includes some purchased services and thus is not identical to the net value added concept that is used in generating GDP. It also has the disadvantage that its deflators are inferior to those available for shipments and that shifts in definitions over time of value-added can potentially lead to bias in time series estimates. On the other hand, shipments, as a measure of output, has the disadvantage that increases in shipments per worker may simply hide a decrease in the degree of vertical integration over time. It turned out not to matter much for the analysis which measure of output was used and we have, therefore, chosen to report the measure used herein.

The short-run analysis is based on a year-to-year change in the relevant variables, generating a time series for the 1973-93 period. For the long-run analysis, the changes are measured over a five-year period in a moving fashion (1973-78, 1974-79 and 1988-93), generating a time series of sixteen observations for the 1973-88 period. Establishments were allowed to move freely from one time period to the next between the job creation and job elimination categories.

\section{Mean Values of Job and Output Changes}

This section presents the mean values of the output and employment change by sector in the short and the long-run. The summary data show large differences in the underlying labour-output adjustment mechanism for establishments that are expanding employment versus those that are downsizing. The short-run and the long-run mean values of job creation, job destruction and the associated output changes by sector and for all of manufacturing are presented in Table 2. Each of these values represents an average of the 6 establishment categories (three size categoriessmall, medium and large - and two control categories - Canadian and foreign).

The table shows that, on an annual basis, the manufacturing sector as a whole created 5,474 new jobs and expanded output by $\$ 526$ million. This translates into a job creation rate of 10 workers per \$million expansion in output. In the long-run (or on 5-year basis), the job creation rate is lower, i.e., 7 workers for every \$million increase in output. This means that, on average, the establishments that grew in the short-run created some 40 percent more new jobs for a given increase in output than did the establishments that grew in the long-run. This pattern was mirrored in all of the constituent sub-sectors, i.e., in each sub-sector, the number of jobs created per dollar expansion in output in the long-run is significantly less than in the short-run. These differences show the need to differentiate the short from the long-run. While it is common to refer to short-run rigidities that interfere with full labour adjustment to changes in demand, these rigidities should not be overemphasized. In the short-run, the adjustments are actually quite a bit

\footnotetext{
${ }^{16}$ As an alternative, value-added could have been used. But the ratio of value of shipments to value-added in the foreign sector compared to the Canadian is virtually constant over much of the period and, therefore, the results are much the same for the two output measures.
} 
larger than long-run labour changes that are associated with adaptation by growing establishments.

Both the short- and long-run employment expansion rates varied across sectors in a fashion that is consistent with labour-intensity differences. As would be expected, the labour-intensive subsector topped all other sectors, hiring 18 workers in the short-run and 12 workers in the long-run, for every \$million increase in output. The scale-based sub-sector, as expected, was at the bottom.

The rankings of the different sectors are more or less the same for both the short and the longrun. As a consequence the ratio of the number of jobs created per dollar of output change in the short to the long-run is tightly distributed around the all-sector mean of 1.5.

When establishments are divided into those expanding versus those contracting employment in the short-run, about the same amount of job change occurs in both populations across all the industries. For the manufacturing sector as a whole, the job turnover in each case is around 5.5 thousand workers per establishment category. This is not the case in the long-run. Job loss is about 30 to 40 percent higher than job gain in the long-run. In the longer run, total jobs in the manufacturing sector are contracting because employment loss in the declining group of establishments is greater, on average, than employment expansion in the growing group.

Employment change must be set in context of output change. The relative size of the contraction in output is very different from its expansion in both the short and long-run, with output change in contracting establishments much less than in expanding establishments. Consequently, in the short-run, the change in employment per dollar of output in contracting establishments is one and half times as large as is occurring in plants expanding employment, i.e., 15 workers versus 10 workers. In the long-run, this ratio is close to two, i.e., 13 workers versus 7 workers. This indicates that establishments that are downsizing have a marginal labour productivity that is considerably higher than those that are expanding employment.

All this indicates that the coefficients from the regressions that estimate the marginal productivity of labour of different groups need to be carefully interpreted. While we have divided the establishment population into those where employment is growing and those where it is declining (because of our inherent interest in these two groups), the latter group should not be exclusively associated with failing establishments. A considerable proportion of establishments that are contracting employment are engaged in labour rationalization. It may be that they are decreasing all inputs (including labour) while they maintain output; it may be that they are substituting labour for capital. In any case, their marginal productivity gains are impressive.

The aggregate results presented in this section do not permit a detailed analysis of the changes in marginal productivity across establishments of different sizes or nationality. For this, regression results using the individual cell data are required. The regression results below provide the relative differences in the marginal responsiveness of job change to output change by sub-sector, nationality of control and plant size class. 


\section{Regression Results}

While we are interested in how establishments whose employment is expanding differ from those who are contracting, we cannot proceed to investigate the differences in the marginal employment coefficients by dividing the sample into those where employment is growing and those where it is declining for the purposes of estimating equation (7). The estimate of $\eta$ would be biased because of sample selection problems that result from having an error term that does not have an expected value of 0.17 The size of the bias will vary from application to application and is expected to be less in the case of this study since observations are grouped by cell and visual inspection suggests few observations were truncated. To resolve this problem, we use observations where shipments increase to calculate coefficients for the expanding group, and observations where shipments decrease for calculating coefficients for the contracting group.

The regressions for expanding and contracting establishments so defined are estimated for each of the six manufacturing sub-sectors (equation 4) and for the whole manufacturing sector (equation 5). In the latter case, a binary variable (FB) is used to distinguish the food and beverage sub-sector from rest of the manufacturing sector. In each case, the results are derived from pooling the observations from each of the cells (defined in terms of industry control and size) over the time period and correcting for serial autocorrelation at the cell level.

The short- and long-run regression results for the expanding establishments are reported in Table 3 . The corresponding results for establishments where shipments were declining are reported in Table 5.

It should be noted that the base coefficient represents small Canadian establishments, while the coefficients on the binary variables ( $\mathrm{S} 2, \mathrm{~S} 3, \mathrm{CF}$ and $\mathrm{FB}$ ) represent the differential response of other establishment categories from the base category. Since the focus of the study is to examine the job responses at the margin, only the slope coefficients are reported (intercepts are omitted). In order to make differences across size classes more transparent, we combined the coefficients that measured differential responses with the base coefficient and constructed actual slope coefficients for each size class of domestic establishments, small foreign establishments, and, in the case of the aggregated data, for small food and beverage establishments. As noted earlier, the size differences observed for domestic establishments also apply to foreign-controlled establishments. These coefficients, along with their standard errors, are reported for expanding establishments in Table 4 and for contracting establishments in Table 6. It should be noted that marginal responses are measured in terms of thousands of workers per billion dollars of change in output but the discussion in the next section is couched in terms of number of workers (jobs) per million dollars of output.

\footnotetext{
${ }^{17}$ Hamermesh (1993) discusses these problems.
} 


\subsection{Output Expansion and Job Creation}

\subsubsection{Short-run Results}

For the manufacturing sector as a whole (denoted by All Sectors in the tables), small Canadian establishments created 10 new jobs for every \$million increase in output (Table 3). Differences across industries in the labour-response rate are the result of differences in fixities, capital intensities and productivity gains. Where there are substantial short-run fixities, employment change will be smaller in the short-run because employment cannot be easily changed. Where capital intensity is high, employment change will be smaller because most of the input change will involve capital and not labour. Where labour productivity gains are greater due to technological change, employment expansion will be less.

By sector, the job-creation response in small establishments varied from 5 jobs in the case of the scale-based sector to 14 jobs for the labour-intensive sector (Figure 5). The labour-intensive and the product-differentiated sectors had relatively high labour response rates relative to the scale sector, with each dominating in different size classes. The natural-resources and science-based sectors also exhibited a very high job creation response in the smaller size classes, but this did not persist as size of establishment increased.

With the exception of the scale-based sector, small Canadian establishments in food and beverages were relatively less responsive than establishments of the same size class in the rest of the manufacturing sector. This is reflected both by the low coefficient in the agrifood sector (7 jobs per \$million dollar increase in shipments) and in the negative value of the coefficient on the food sector binary variable (FB) in the all-sector case.

Larger establishment size reduces the response of job creation to output changes in the short-run. The medium and large size establishments in the manufacturing sector created roughly 50 percent fewer jobs than small establishments, i.e., 5 jobs compared to 10 jobs for each $\$$ million expansion in output (Table 4). The significant differences between small establishments and all other establishments were also observed among the constituent industry groups as well. Medium establishments generally do not have significantly different responses from large establishments.

The difference in the response across size classes is indicative of intra-industry technological differences. The difference across size classes was wider in the case of the natural-resources, labour-intensive, and science-based sectors; it was smallest in the scale-based sector. The scalebased sector not only has the smallest reaction generally to output changes but also has the least difference across size classes, thereby suggesting that large and small plants are quite alike with regards to short-run fixities. On the other hand, the wide size-class differences in the naturalresources, labour-intensive, and science-based sectors suggest that, in the short-run, small and large plants here face very different constraints caused by fixities. This also suggests that these sectors are characterised by a wide intra-industry variation in technologies. 
When foreign-controlled establishments increase output, they create fewer new jobs in the shortrun than their Canadian counterparts, since the coefficient on the binary variable for foreign control (CF) is negative in all cases (Table 3). For the total manufacturing sector, establishments controlled from abroad in the smallest size category hired roughly 50 percent fewer employees for a given increase in output (Table 4). For the medium and large size categories, the difference between Canadian and foreign plants is even more pronounced (i.e., 5 jobs versus less than 1). That is, foreign plants expanded output with a relatively small increase in employment. The foreign-control impact is generally statistically significant, with the exception being food and beverages.

Since most of the foreign establishments are large and most Canadian establishments are small, this result reinforces the differences between the two groups. Foreign-controlled establishments will have a higher short-run marginal labour productivity, both because they are larger and because in the larger size group they are more productive. A given expansion in output in the foreign-controlled sector is accompanied by a smaller increase in the number of new jobs than at small establishments, which are mostly Canadian-controlled. This suggests that, at the level of the sectors being used here for estimation purposes, foreign and Canadian establishments employ technologies that are characterized by significantly different factor intensities.

\subsubsection{Long-run Results}

The most striking difference between the short- and long-run results is the significant decline in the job responsiveness of establishments to output increases, especially in the smallest size classes (Figure 6). For example, in the all-sector case, the small Canadian establishments at the margin registered a net increase of 7 jobs for every \$million increment in the value of real output over a 5-year period compared to 10 jobs for the same category in the short-run (Table 4). The decline is less dramatic for medium and large establishments (Figures 7 and 8, respectively). Indeed, it is only found in two sectors for large plants. However, the effect of foreign ownership has increased slightly. For example, in the small size category, these plants now hire almost 60 percent fewer employees (i.e., 3 versus 7) than domestic plants (Table 4).

It should be noted that, in addition to the higher rate of substitution between labour and capital that is possible in the long-run, there may be other factors contributing to the relatively lower job creation rate. For example, it may be that the cross-section of establishments included in the short-run and long-run analyses have significantly different technologies, and hence capital/labour ratios. Further, part of a lower job response to output expansion for some types of establishments (e.g. large) may also be attributed to other characteristics of output markets. For example, it is possible that the longer an establishment grows (conferring stability) or the larger it is (with economies of scale in $R \& D$ ), the more it can afford to venture into the production of high value-added products, augmenting the expansion of output with little or no impact on labour input use. 
Figure 5

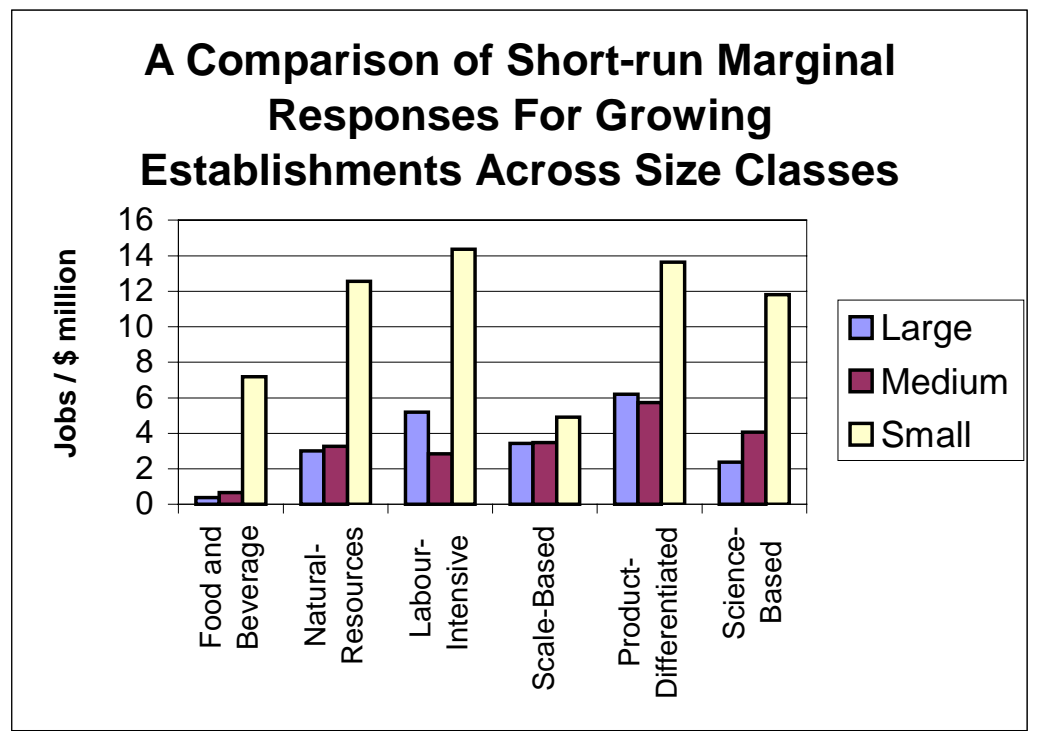

Figure 6

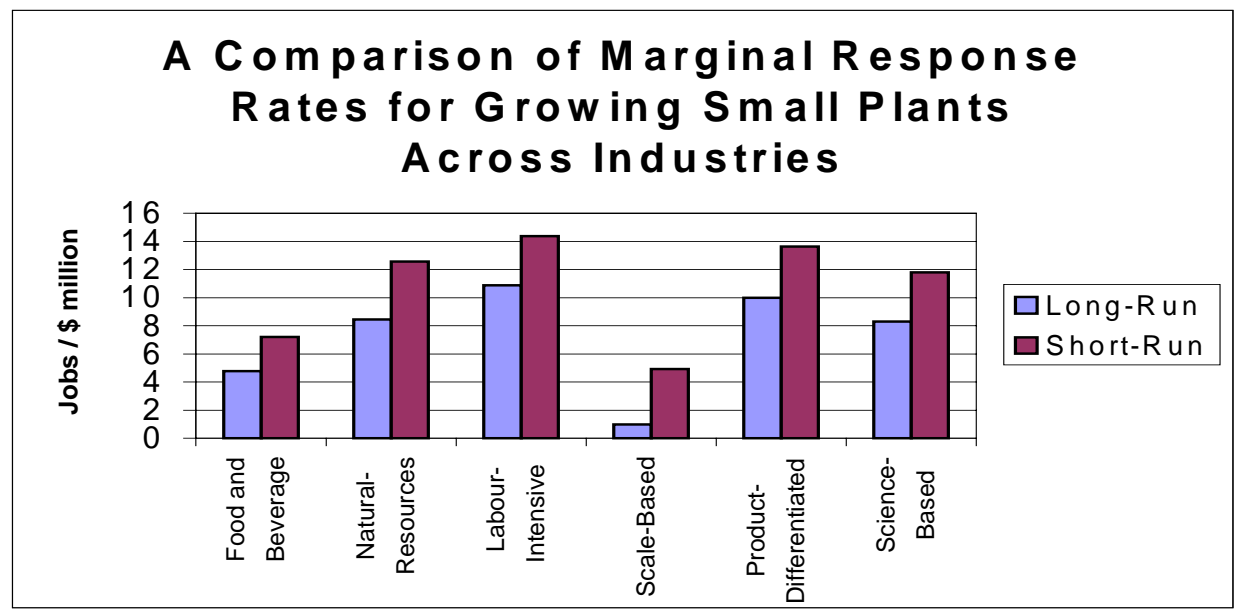

Figure 7

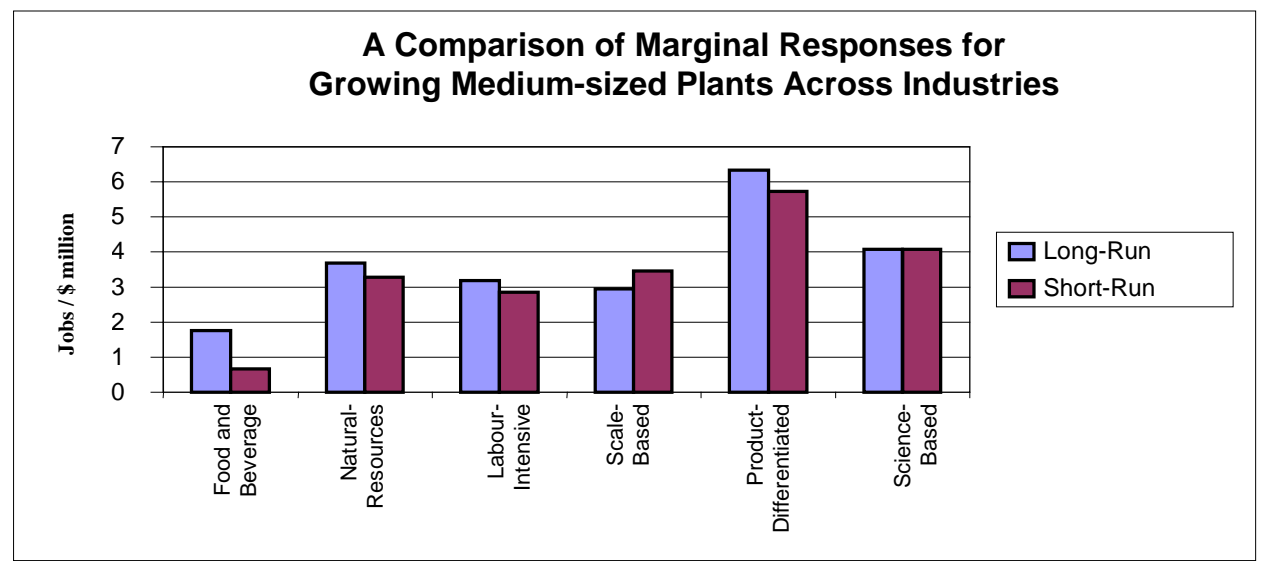


Despite these differences between the short and long-run, the interindustry rankings are similar in most of the cases. The two sectors with the lowest short-run response for small plants (scalebased and food and beverages) also have the lowest long-run responses as well (Figure 6). On the other hand, the two sectors with the largest short-run responses (labour-intensive, and product-differentiated) also have the largest long-run responses. While the differences between the short and long-run show that there are possibilities of economizing on labour in the long-run, the underlying differences in capital intensity lead to similar intersectoral differences in both the short and long-run.

While the intersectoral rankings in levels are basically unchanged between the short and the long-run, the differences between the labour adjustment coefficient for the small and large establishments are not. In all sectors, the small size plants increase employment at a significantly lower rate in the long-run than in the short-run. This stems from the fact that the small size class is made up predominantly of new establishments. Differences between short and long-run reflect the fact that new establishments are relatively unproductive when they start but increase their productivity if they survive (See Baldwin, 1995). The same differences are not found between the short- and long-run responses of medium and large size plants in many sectors. For example, the medium size plants in the food and beverage, natural resources, labour-intensive, productdifferentiated and science-based industries actually exhibit a higher labour response in the longrun (Figure 7) than in the short-run. Here we have evidence that establishments are constrained in the short-run from adjusting fully but have less of a problem in doing so in the longer run. The net result has been a dampening of the intra-industry variation in the long-run labour-output adjustment behavior across size classes relative to the short-run.

In the long-run, foreign-controlled establishments continue to have a higher marginal labour productivity, since the foreign-control coefficient Table 3 is negative. The coefficient is highly significant in all but the labour-intensive and scale-based sectors. This indicates that the long-run marginal labour productivity of foreign-controlled establishments is generally superior to that of domestic establishments. In the food and beverage sector, the foreign-controlled establishments significantly outperform the domestic establishments in the long-run, but not in the short-run.

\section{Figure 8}

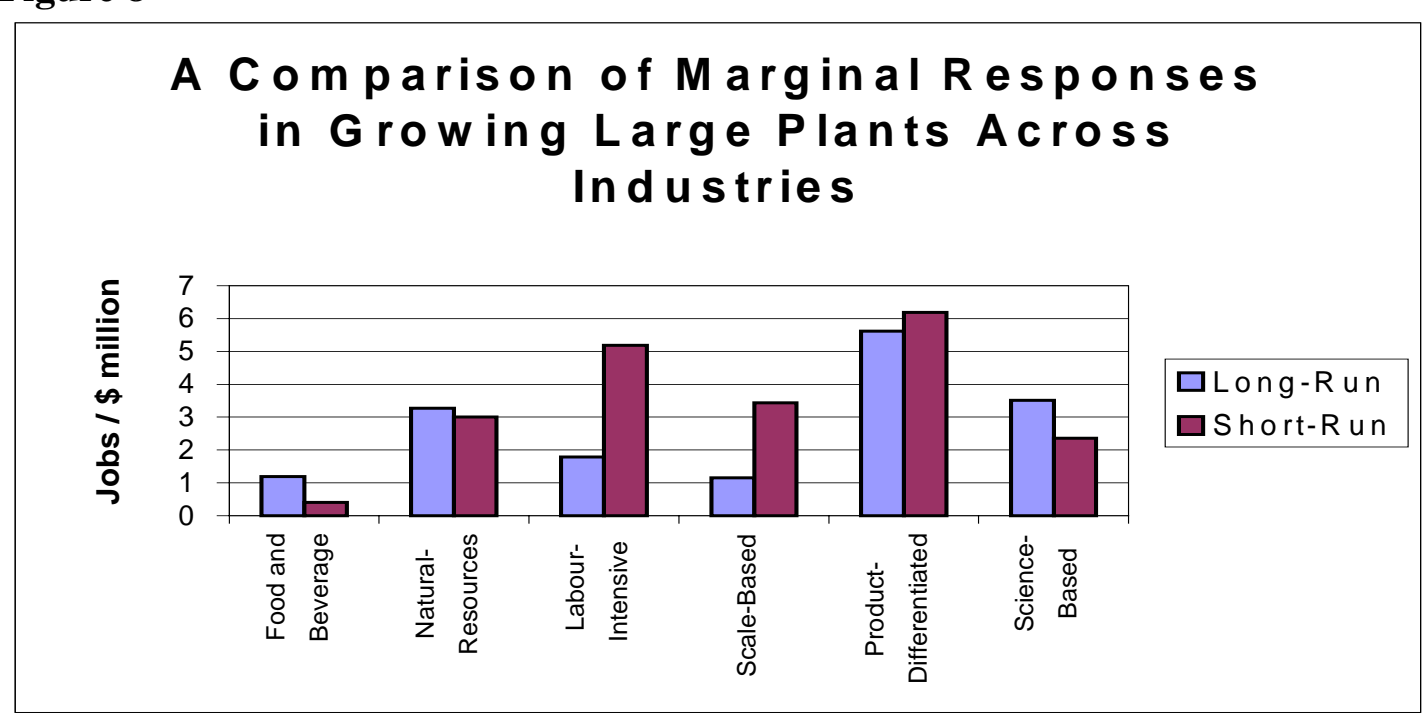


Figure 9

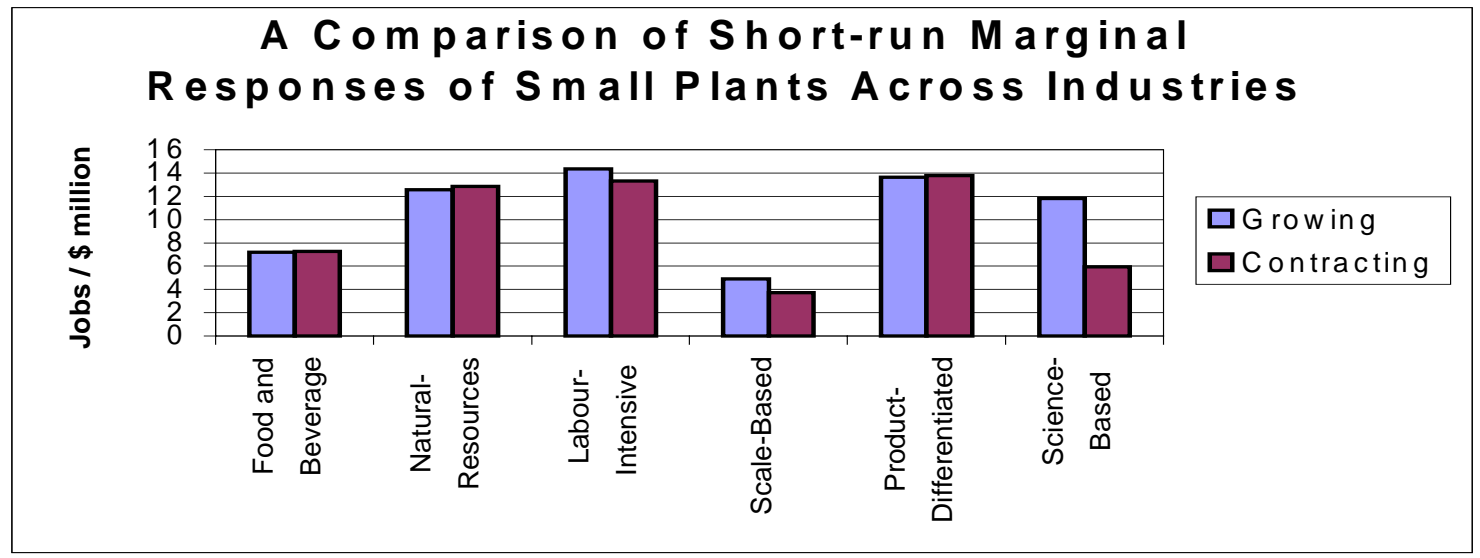

Figure 10

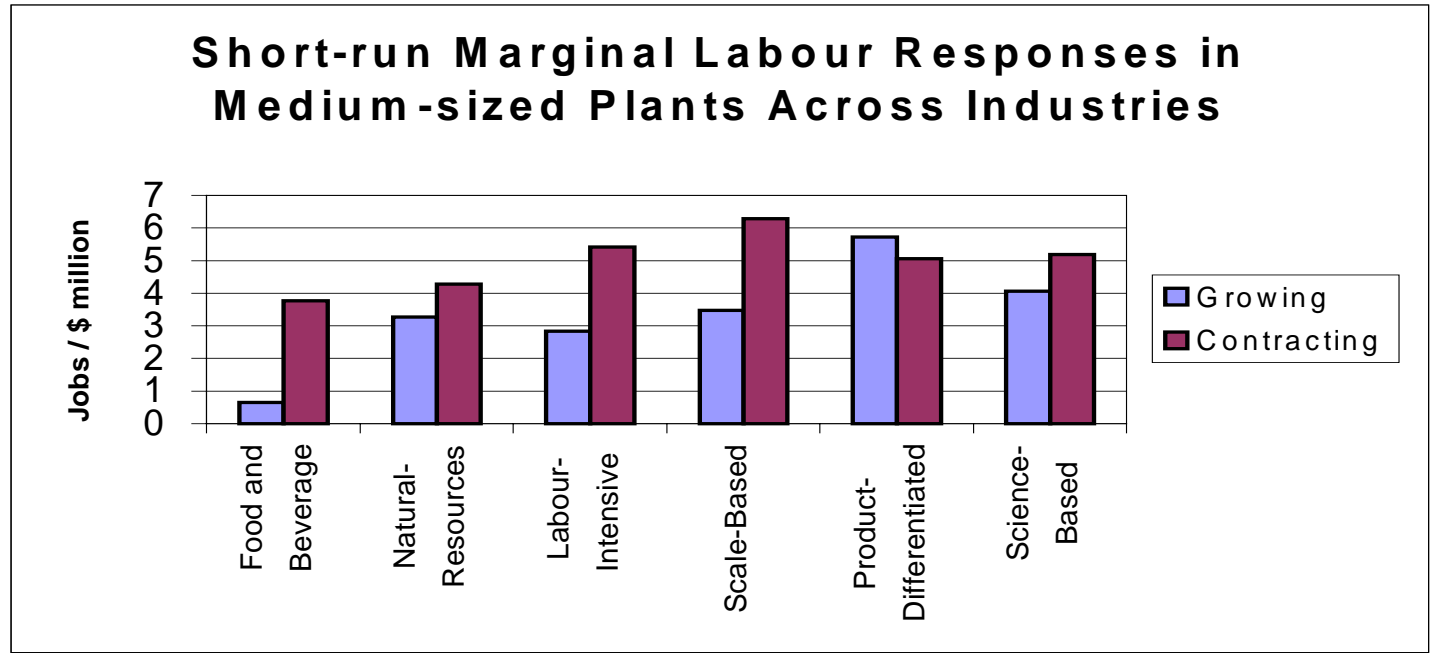

Figure 11

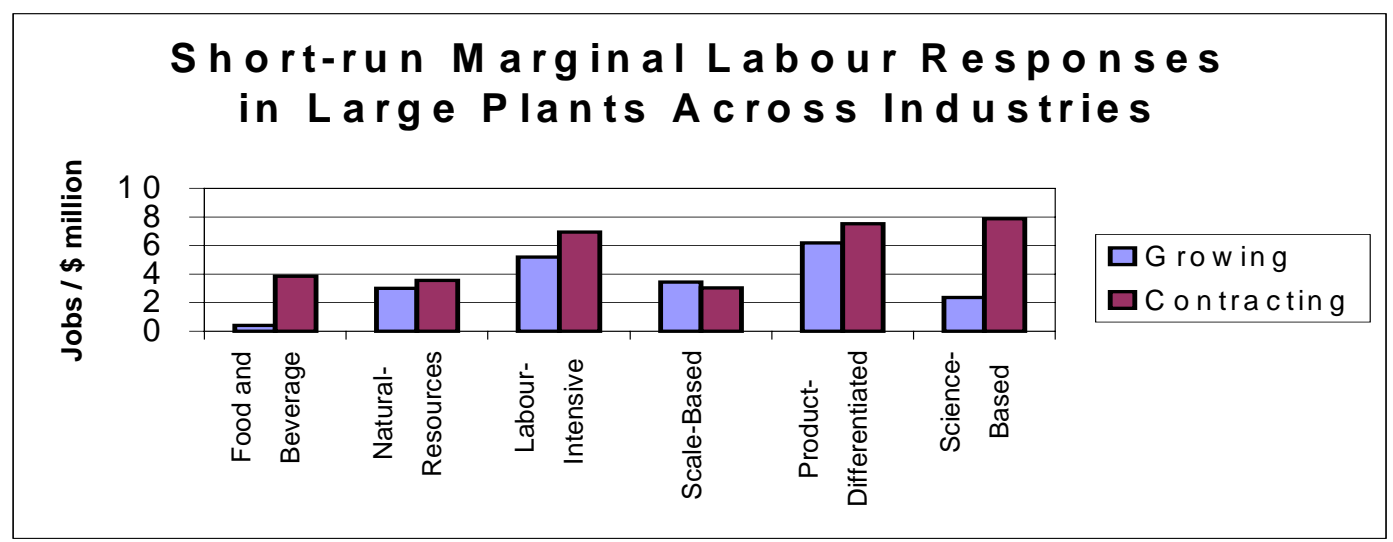




\subsection{Output Contraction and Job Destruction}

\subsubsection{Short-run Results}

Occasionally, it is suggested that fixed costs should make adjustment asymmetric - that labour adjustment downward will be less than when expansion occurs. This is not found in the case here (Figure 9). On average, the small contracting establishments in the manufacturing sector eliminated roughly the same number of jobs for a given contraction in output (Table 5) as did the growing establishments in response to a given increase in output (Table 3). For example, small establishments, on average, laid off 10.4 workers for every \$million decline in production (Table 5), while the corresponding increase for small growing establishments was 9.8 workers (Table $3)$. This pattern was mirrored across all constituent industries, with the exception of the sciencebased sector where the lay-off rate in small contracting plants is one-half of the job creation rate in the small expanding plants. This indicates that, in the short-run, the inflexibilities in the adjustment mechanism are very similar between small expanding and small contracting plants.

Contrary to the small-establishment group, the medium- and large-sized establishments exhibit a 'downward' adjustment that is generally greater than the 'upward' adjustment in all sectors (Figures 10 and 11). Thus, there is evidence of more inflexibilities in the upward than the downward direction.

The short-run job adjustment response for small contracting establishments varied from 4 jobs in the case of the science-based sector to 14 for the product-differentiated sector. Except for the scale-based sector, the ranking by sector for marginal labour adjustment in contracting establishments is similar to the ranking for job-creating establishments. For example, in the smallest size class, the labour-intensive, natural-resources, and product-differentiated industries have a high rate of adjustment for both growing and contracting establishments, while the food and beverages and scale sectors are at the low end for both. The one exception to this is found in the science-based industries, which have a high rate of adjustment for growth, but a low rate for labour contraction. This suggests that, in the case of the science-based industries, workers embody skills that are sufficiently rare that labour is treated more as a fixed asset and laid off only slowly as output contracts.

The comparability of rankings for short-run expansion and contraction in the smallest size class generally extends to the largest size classes, with one major exception. The scale-based industries move up from last place. That is, unlike their small cousins, the large establishments in the scale-based sector have no tendency to lag behind all others during the contraction phase.

The same directional effect in terms of adjustment that was found for job growth across size classes is also found for job contraction (Table 5). For a given contraction in output, the medium sized establishments in all sectors downsized their work force to a lesser extent than did small establishments (e.g., 5 jobs against 10 jobs in the total manufacturing sector). In some of the sectors, the overall job response to output contraction declined further for the large establishments. For the manufacturing sector as a whole, there was an overall decline of roughly 1.6 additional workers per \$million change in output, when all groups in manufacturing are considered together. Once again, small establishments are seen to have a greater volatility in terms of short-run change. 
Figure 12

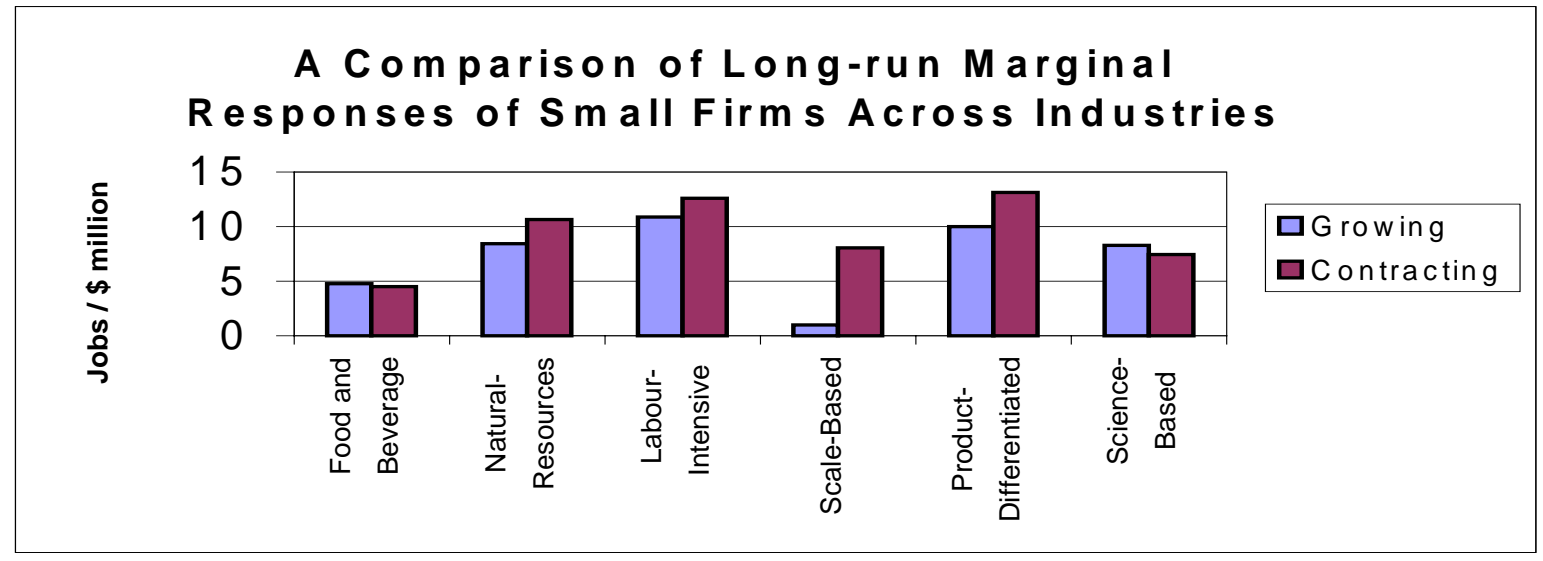

Figure 13

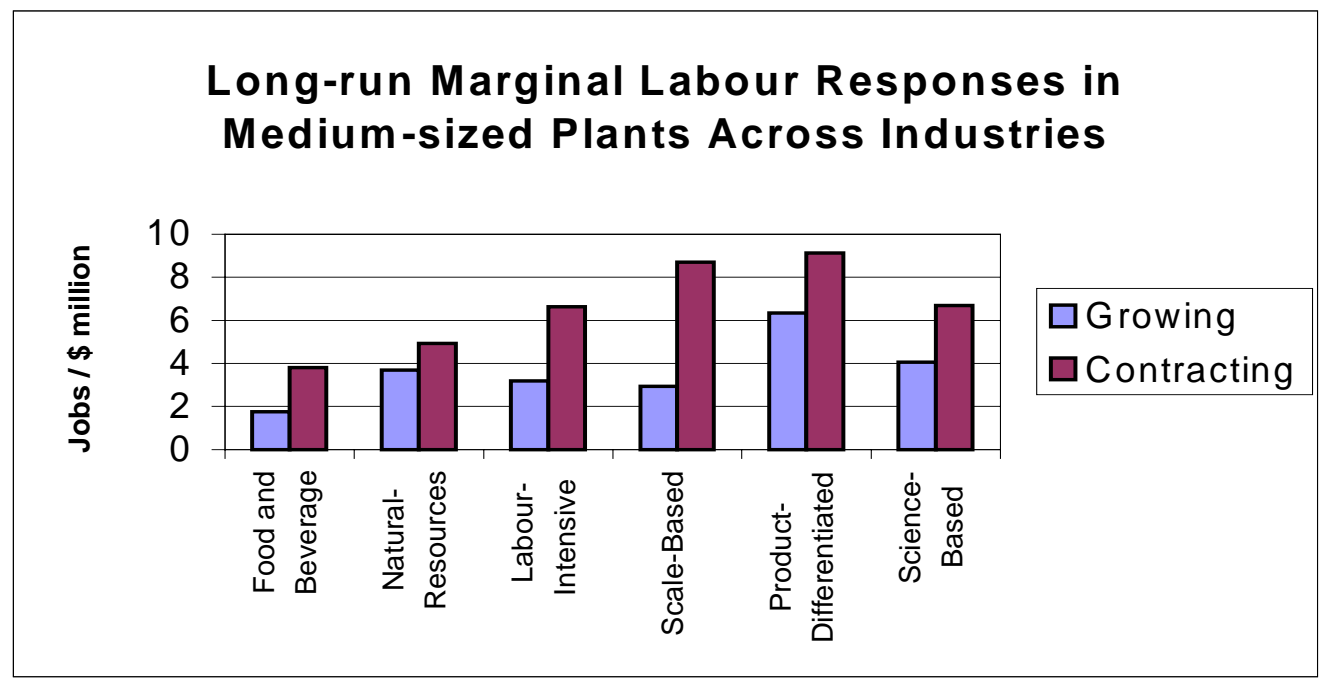

Figure 14

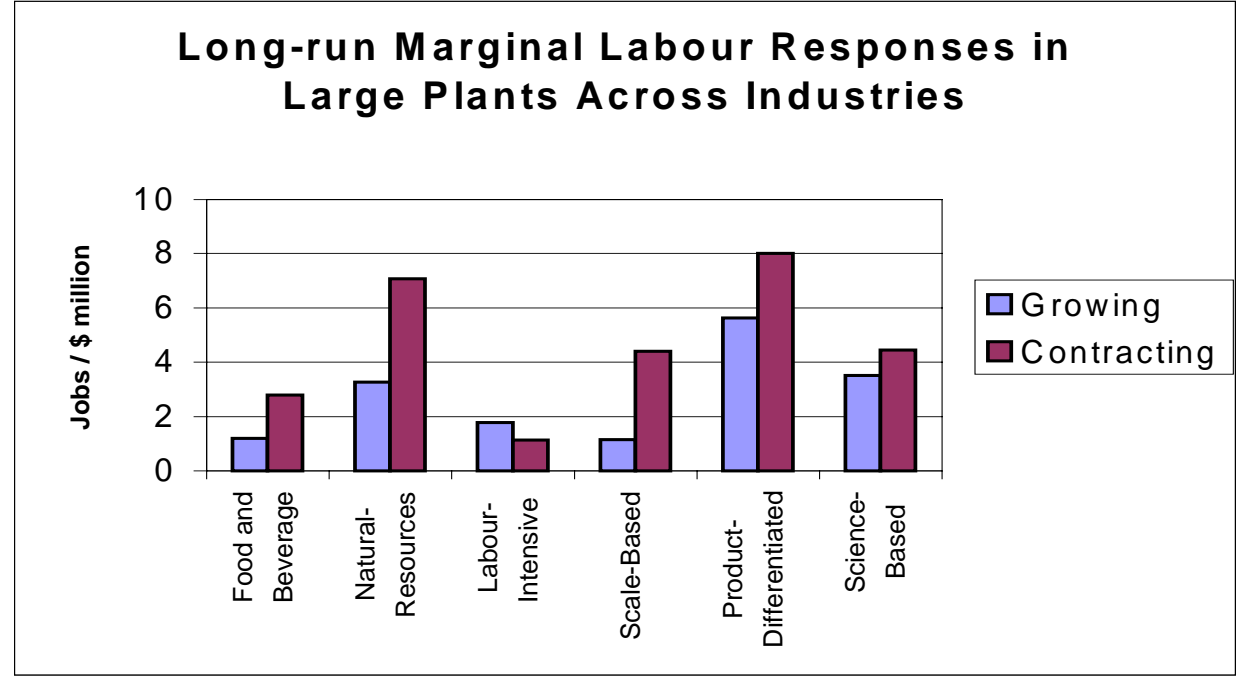


The downsizing of the work force at the foreign-controlled establishments in each size category is smaller relative to output change than at the Canadian-controlled establishments. For all sectors, the foreign-controlled establishments in all size categories eliminated 1.6 fewer jobs for every \$million contraction in output than did their domestic counterparts (Table 5). However, the effect of foreign-control is much smaller (only about 20\%) in the contraction phase than in the expansion phase, where such plants added 50 percent fewer workers than the domesticallycontrolled plants. Food and beverages are the only industries where the foreign-owned plants lay off more workers than their domestic counterparts for a given contraction in output. It may be noted that in the expansion phase, foreign ownership did not have a significantly different effect on job creation in this sector.

\subsubsection{Long-run Results}

For output expansion in small establishments, the labour adjustment coefficients were higher in the short than the long-run. However, in the contraction phase, the short and long-run coefficients are very similar across all industries for these small establishments (Figure 12). For example, small establishments in the manufacturing sector as a whole downsized at the rate of 10.9 workers in the long-run for every \$million contraction in production, compared with 10.4 in the short-run; the corresponding short- and long-run figures for job growth were 10 and 7 , respectively. This suggests that a process is in play for output gainers in the small size classes where the transition from short-run to long-run is more than offset by productivity gains in the long-run. A greater ability to adjust in the long-run would increase the adjustment coefficient while productivity changes should decrease it. The fact that the coefficient falls in the long-run suggests that the productivity effect is dominant. However, for plants where output has contracted, the two effects should increase the coefficient. That the long-run coefficient is about the same as the short-run coefficient suggests that adjustment effects are not much larger when we move beyond a one-year time horizon and that productivity improvements from downsizing do not increase as the time period is lengthened. But then that is not unexpected since the room for downward rationalization for small establishments is limited.

On the other hand, in the medium and large size classes, adjustment in contracting establishments is slightly greater in the long than the short-run, whereas the reverse holds for expansion (Figures 13 and 14). In both cases, then, there is weak evidence pointing to productivity adjustments that are implemented over a longer time period.

There are some asymmetries in the long-run adjustment process. In the long-run, small Canadian growing establishments added 7 jobs when output expanded by \$1million (Table 4). Small contracting establishments, on the other hand, laid off 11 workers for a similar contraction in output (Table 6). Likewise, small foreign establishments added 4 workers in the expansion phase and laid off 7 workers in the contraction phase. Small establishments then showed more downward adjustment than upward adjustment. 
Once more, the larger size classes differed from the smaller size classes. The medium and large size units in the manufacturing sector as a whole expanded and contracted at much the same rate-between 4 to 7 workers for every \$million change in output.

Thus, these data show that contracting establishments should not be depicted as unsuccessful when it comes to increases in productivity. However, the impact of these marginal changes on each categories' respective average labour productivity depends on a number of other factors. Since the issue of the difference in average labour productivity of expanding and contracting establishments is of interest, it will be more fully explored in the following section.

\section{Changes in Labour Productivity}

In the preceding section, we examined the relative importance of plant size and nationality of ownership on the marginal productivity of labour-how changes in labour employed respond to changes in output. In this section, we extend the analysis by investigating how the average productivity of labour changes as a result of the growth and contraction process. As before, growth and contraction are treated separately and to avoid the sample selection problem, the population is divided into those with growth and contraction in output. Once more, the analysis is performed both for the short-run and long-run. The scope of this analysis is restricted to the food and beverage sector and the rest of the manufacturing industries; the latter combines the natural resources, labour-intensive, scale-based, product-differentiated and science-based industries into one group.

The change in average labour productivity $\left(\Delta A P_{\mathrm{t}}\right)$ is expressed in ratio form. The formula is:

$$
\begin{array}{ll}
\Delta A P_{\mathrm{j}}= & A P_{\mathrm{t}+\mathrm{j}} / A P_{\mathrm{t}} \text { where } \\
A P_{\mathrm{t}}= & \text { total shipments in period } \mathrm{t} \text { divided by the total employment in period } \mathrm{t} \\
A P_{\mathrm{t}+\mathrm{j}}= & \text { total shipments in period } \mathrm{t}+\mathrm{j} \text { divided by the total shipments in period } \mathrm{t} \\
\mathrm{t} & =\text { represents the } 1973-92 \text { period for the short-run (annual) analysis and } \\
& 1973-1988 \text { period for the long-run ( } 5 \text { year) analysis } \\
\mathrm{J} & 1 \text { for the short-run (annual) analysis } \\
= & 5 \text { for the long-run ( } 5 \text { year) analysis }
\end{array}
$$

$\triangle A P_{\mathrm{j}}$ is calculated for growing, declining and for all establishments together, and in each case by size and control. In each case, the shipment and employment data correspond to a particular group of establishments (defined in terms of sector, control and size). All shipments are measured in real terms by dividing the nominal values at the establishment level by the output price index of the corresponding 4-digit (SIC80) industry.

$\triangle A P_{\mathrm{j}}$ equals one when the marginal changes in output and employment do not alter the average labour productivity, i.e. marginal productivity equals average productivity. This happens when, at the margin, scale economies are absent, the capital-labour ratio of the plant remains unchanged, or no efficiency improvements take place. When $\triangle A P_{\mathrm{j}}$ is greater than one, average labour productivity has improved as a result of the marginal changes in employment and output changes. For growing establishments, this happens when a given increment in employment is 
accompanied by a relatively larger expansion in output. This could occur when plants adopt advanced technologies, and/or become more capital intensive and more productive than before. The presence of significant scale economies could also result in an improvement in the efficiency of all inputs, including labour. Finally, it could occur if employment expansion is concentrated in operations that bring the largest marginal gain in performance and profitability.

For the contracting segment of establishments, a gain in average labour productivity $\left(\triangle A P_{\mathrm{j}}>1\right)$ occurs when a contraction in output is accompanied by a relatively large contraction in employment. This could arise because the most inefficient operations are closed down first, or alternatively, the least productive members of the labour force are let go first. The gain in labour productivity for contracting plants could also occur as the result of restructuring that boosts the capital-labour ratio.

A loss in or deterioration of the average labour productivity occurs when $\triangle A P_{\mathrm{j}}$ is less than one. In the expansion phase, this could occur when mature, less efficient plants (either new entrants or firms that are in the early stages of the product cycle) are responsible for most of the expansion in output. In the contraction phase, it can happen if downsizing significantly reduces the efficiency of all factors of production. Fixity of labour inputs could also cause average labour productivity to decline when output falls.

As indicated previously, examining changes in average productivity in both short- and long-run, by size class, and by nationality of control reveals important information about differences in the growth process within the establishment population. The differences between the short- and long-run reveal the importance of input fixities, factor substitution, technology development, and scale economies. The distinction by nationality of control (domestic versus foreign) captures the influence of firm-specific factors, such as technology, management, and other factor costs. Size differences allow us to understand the respective contribution of small versus large establishments.

\subsection{Mean Values of Average Productivity Gains (Losses)}

The short- and long-run mean values of $\Delta A P_{\mathrm{j}}$ (averaged over the sample period) for growing plants, contracting plants, and all plants taken together, and in each case broken down by control and size, are reported in Tables 7 and 8, for the food and beverage industries and rest of the manufacturing sector, respectively.

\section{a) Food and Beverage Sector}

Generally, growing establishments have less of an increase in average productivity than those contracting (Figure 15 and Table 7). In the short-run, the annual increase in the average labour productivity for contracting plants ranged from 5 percent to 17 percent, while in the long-run (over a 5 year period), it was in the 15-36 percent range. In contrast, expanding plants in each category showed less of an increase in average productivity and actually a decline in the smallest size class. 
The net effect of growing and contracting plants on the overall labour productivity of the food and beverage sector reveals that the strong positive showing of establishments in the contraction phase outweighs their relatively weak or negative showing in the expansion phase. As a result, the marginal changes led to an improvement in the overall labour productivity in almost all segments of the sector (Figure 16). The only exceptions are the small plants where the marginal changes are almost productivity-neutral in the short-run.

There are also substantial differences across size classes and these differences operate in different directions for growing and contracting plants. For domestic growers, larger size classes increase productivity the most, the smallest size classes the least (Figure 15). The reverse is true for the contracting domestic class of plants. This difference comes primarily from the behaviour of the smallest size class - the class that contains most of the entry and exits of establishments that take place in the population. It is in this class that average productivity falls for growing establishments and declining establishments have much higher average productivity growth than the other two size classes. This peculiar result arises from the importance of entry and exit herein and the fact that new establishments initially are less productive than incumbent establishments and that most of the inefficient subsequently exit (See Baldwin and Rafiquzzaman, 1995). The appearance of entrants in smallest size classes drags down productivity therein and their demise has the opposite effect. But, on balance, their net effect (the all-plant column) is neutral in the short-run for the smallest classes. It is the case, however, that the larger size classes have a larger positive increase in the short-run when both growing and contracting plants are averaged.

In the long-run, some of the size-class effect is reduced as small establishments grow and improve their relative importance and the largest size class reduces its performance, so that the two are about the same-with the middle size class showing the largest improvements in average labour productivity for domestic establishments.

The same gradations across size classes can also be discerned for foreign-controlled establishments. The net effect observed in the smallest size class is also neutral in the short-run but it increases more in the long-run for the foreign controlled sector-but then it does so across all size classes. It is in the foreign sector that the largest differences occur across size classesbut this occurs not so much because small establishments make little progress, but rather because the largest have such large productivity increases.

Foreign establishments generally have higher rates of productivity increases. The domestically controlled establishments improved their overall labour productivity by about 3 percent in the short-run and between 5-10 percent in the long-run. The gains are relatively higher at plants managed from abroad; they range from 4 percent in the short-run to almost 18 percent in the long-run. The one category where foreign controlled average productivity increases are not higher is for contracting plants in the smallest size class where exit effects are quite different. This is because foreign controlled entrants tend to be relatively more productive and the same degree of churning due to entry and exit does not occur in new foreign-controlled establishments. 
Figure 15

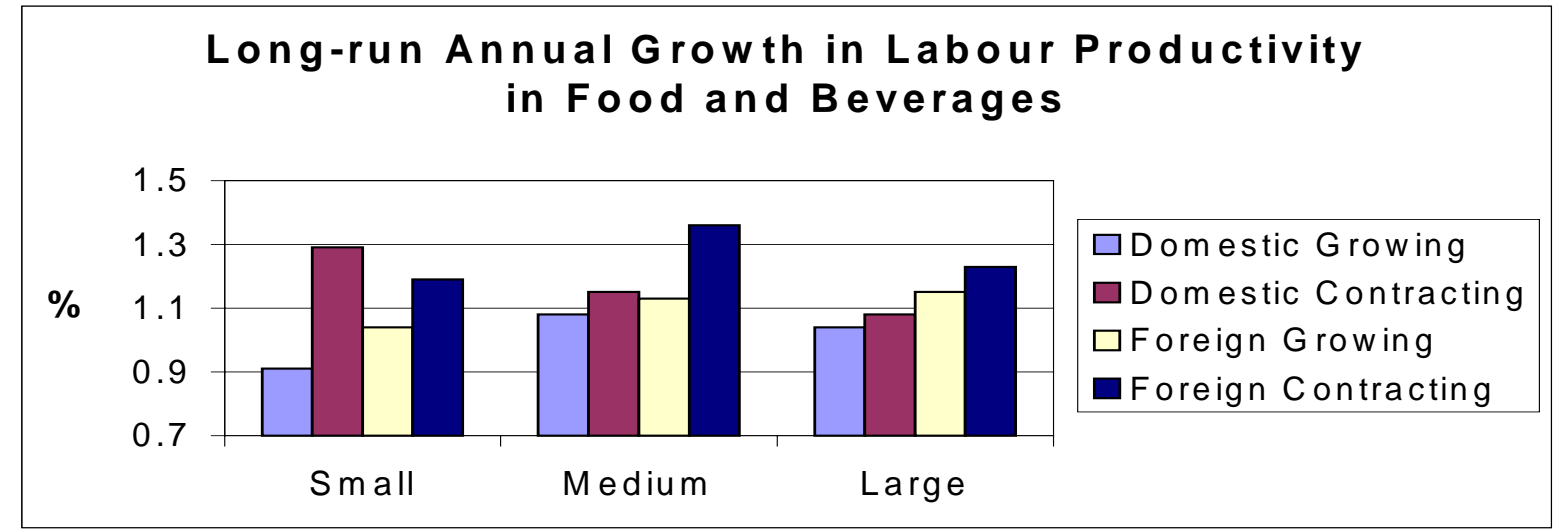

Figure 16

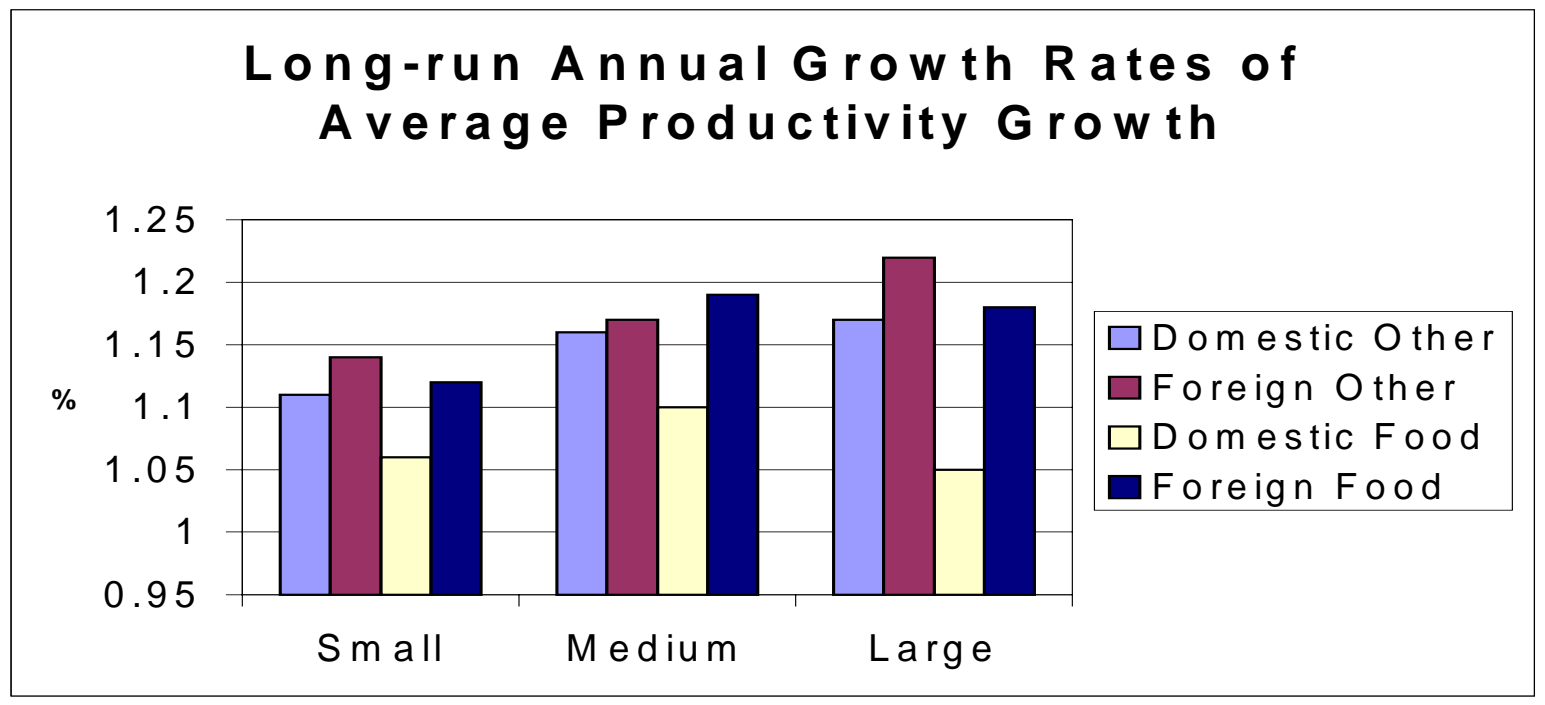

Figure 17

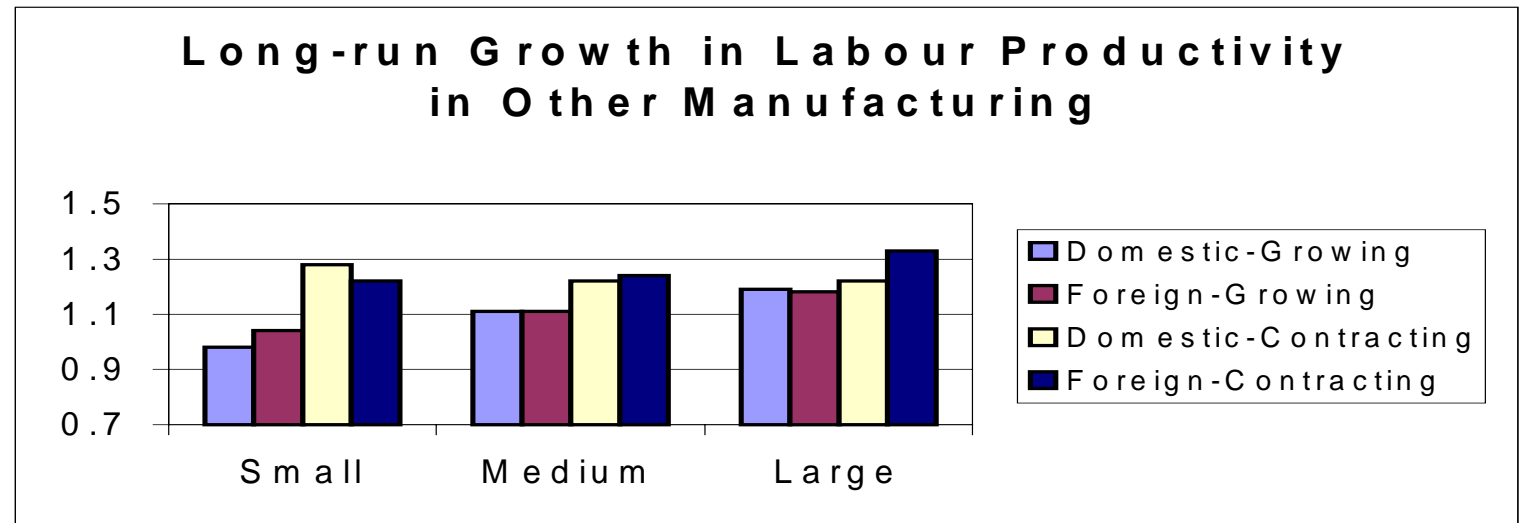


The differences between domestic and foreign sectors are generally higher in the long- than in the short-run for each size class. This suggests that the differences that exist between the foreign and domestic sector are difficult to see in the short-run because of similar reactions to macroeconomic fluctuations-but that growth over time tends to differentiate the two groups.

\section{b) Other Manufacturing Sector}

For the rest of the manufacturing industries, the pattern of changes both across growing and contracting, small and large, as well as domestic and foreign controlled groups are quite similar to those of the food and beverage sector discussed above (Table 8).

First, larger plants experience greater increases in average productivity than the smallest plants (Figure 17). However, the size effect is more noticeable in the other manufacturing industries, in that the largest size class experiences increases that are at least as large as the middle size classes.

Second, foreign-controlled plants always perform better than domestic plants in the food sector. But, the benefit of being controlled from abroad is slightly less in the rest of the manufacturing sector. For plants that expanded in the long-run, the foreign-controlled small, medium and large plants led their Canadian counterparts by 13,5 and 11 percentage points respectively in the food and beverage industries and only 6,0 and -1 percentage points in the rest of the manufacturing sector.

Finally, the net result of labour-output adjustment on the overall or sectoral average labour productivity is always positive for all segments of the rest of the manufacturing sector and it ranged from 1 to 5 percent in the short-run and from 11 to 22 percent in the long-run. These net gains are generally higher than found in the case of the food and beverage industries (Figure 6).

\subsection{Trends in the Impact of Size and Control on Average Labour Productivity Growth}

Of critical interest is the extent to which the differences outlined in the previous section across size classes and nationality of control have been stable over time, declining or growing.

During the period under study, Canada's economy has become more open. Tariff rates have fallen and trade as a percentage of GDP has increased. This may have allowed Canadian controlled plants to increase their scale and improve their relative productivity. On the other hand, technological change has been rapid, with the spread of new computer-based technologies (See Baldwin and Sabourin, 1995). Foreign-controlled plants have been quicker to make use of these new technologies (Baldwin and Diverty, 1995). It is, therefore, of considerable interest to know whether the advantage of foreign establishments has been trending upward.

At the same time, the extent to which productivity differences have been changing across size classes is of interest since an increasing amount of employment is found in smaller establishments (Baldwin and Picot,1995). However, small establishments are much less intensive 
adopters of new technologies (Baldwin and Sabourin, 1995; Baldwin and Diverty, 1995) and the relative productivity of small establishments has fallen over the period (Baldwin, 1998). The decline in relative productivity, combined with the increasing share of employment accounted for by this group, has accounted for part of the productivity slowdown experienced by the Canadian manufacturing sector (Baldwin, 1996).

Investigating whether this decline is simply the result of the increasing importance of small domestic plants or whether it is the result of peculiarities of specific subsectors requires that changes in average productivity be tracked over time and compared across size classes, industry and nationality of control.

To do so, we tested whether changes in labour productivity exhibited any time trend, and whether these trends are statistically different by nationality of control and by size class. We employed the following regressions on the time series data used to construct the mean values given in Tables 7 and 8. The length of time series is 1973-92 for the annual growth and 19731988 for the 5-year growth. The regression used was

$$
\Delta A P_{j}=\mathrm{f}\left(\mathrm{S}_{2}, \mathrm{~S}_{3}, \mathrm{CF}, \text { Trend, } \mathrm{S}_{2} * \text { Trend, } \mathrm{S}_{3} * \text { Trend, } \mathrm{CF} * \text { Trend }\right)
$$

where TREND is a variable taking values from 0 to 19 for the annual changes and from 0 to 15 for the 5-year changes and the other size $\left(\mathrm{S}_{2}, \mathrm{~S}_{3}\right)$ and nationality $(\mathrm{CF})$ variables are the same that were used previously. The results for the food and beverage industries are presented in Table 9 and for the rest of the manufacturing sector in Table 10. Below we discuss results for the longrun analysis only. We further restrict our discussion by comparing the results for small and large size plants, for the performance of the medium size plants generally falls between the two polar categories.

\section{a) Food and Beverage Sector}

In the previous section, we showed that large growing plants had a significant edge over their small counterparts in terms of the effect of marginal changes on average labour productivity; on average, it was 14 and 9 percentage points for the Canadian- and foreign-controlled plants, respectively. The regression results for both the short- and long-run presented in Table 9 show that the gap between the two rates of changes widens over time (the negative coefficient on TREND, which captures the trend in small plants and the positive coefficient for $\mathrm{S}_{3} *$ Trend representing large plants).

For contracting plants, productivity improvements were larger for small plants than for large plants; the difference between the two was 12 percentage points for the Canadian plants and 3 percentage points for the foreign-controlled plants, thereby indicating that this phenomenon was being driven primarily by the domestic sector. This gap in labour productivity gain is stable over time-all coefficients involving TREND in both the short- and long-run are insignificant.

\footnotetext{
${ }^{18}$ We also experimented with interaction terms between the size variables and the foreign-control variable. This did not affect our results in any meaningful fashion.
} 
The net effect of growing and contracting plants is reflected in the coefficients in the all-plants regression. Here, the gap between small and large plants gets larger over time-in that the trend variable (representing the small sector) has a significantly negative coefficient and that the trend variables for the middle and largest size classes are positive and significant. This result is largely being driven by the size-class differences in the growing sector.

The difference between domestic and foreign-controlled plants at the beginning of the period was not statistically significant (the coefficient on CF is insignificant). However, the difference between the two increases over time (the coefficient on $\mathrm{CF}^{*}$ Trend is positive and significant in the long-run). Thus, the effect of foreign control on the rate of increase in labour productivity has grown larger over the period studied here.

\section{b) Manufacturing Sector Excluding Food and Beverage Sector}

The results for the rest of the manufacturing sector are very similar to those for the food and beverage sector discussed above. In both cases, small growing establishments are less productive than their large counterparts and the trend over time increases the difference. Differences occur between agriculture and the rest of the manufacturing sector in downsizing plants. Large plants in the more aggregated sector tend to become more and more successful downsizers over time whereas this effect is not significant for both the short and long run in food and beverages. The coefficient on $\mathrm{S}_{3} *$ Trend is positive and significant for both the short- and long- run in the rest of the manufacturing sector whereas it is positive but insignificant for food and beverages.

While the results of Table 10 aggregate all sectors together, we also examined the trend at each of the sectoral levels - for natural-resources, scale-based, labour-intensive, product differentiated and science-based industries. The trend variable for the largest size class is positive and significant for all but the labour-intensive sector. The size effects that have been reported are found then across a wide range of industries.

As in the food and beverage sector, the gap between foreign-controlled and domestic establishments in the rest of the manufacturing sector increased over time (as indicated by the positive and significant coefficient on $\mathrm{CF}^{*}$ Trend in Table 10 for the long-run). While this trend is not evident in the contracting sector, it is found in the all-plants equation. However, the effect of foreign control is stronger, more significant, and more widely spread across both growing and contracting plants in the case of the food and beverage industries than for other sectors. Elsewhere, this nationality effect is strongest and most significant in the scale-based sector, the product-differentiated and the natural resources sectors. 


\section{Summary}

If we are to study employment growth and how firms are responding to output changes, we must be cognisant of the extent of heterogeneity in the population. That is the reason we have divided the population here into establishments that are increasing their demand for labour and those that are contracting their labour force. Asymmetries in the labour-adjustment response for some groups confirm that they represent quite different populations. For medium size and large plants, the short-run rate of adjustment is greater in the contraction phase than in the expansion phaseat least when measured in terms of jobs per dollar change in output. There are inflexibilities in the short-run in both phases, but they appear to be slightly greater for those expanding employment than for those contracting employment.

These asymmetries are even greater in the long-run (as measured over five-year periods here). Contracting establishments decreased employment by much more relative to output loss than did expanding establishments increase employment per dollar of output gain. Since large coefficients in the former and small coefficients in the latter are associated with greater gains in labour productivity, both groups experience larger gains in labour productivity in the long-run.

There are also substantial differences in the adjustment process across size classes. In the shortrun, for a given increase in output, the smaller manufacturing establishments add more to employment than do larger units. This is also the case for those contracting employment where, for a given contraction in output, there is a greater contraction in employment. This indicates that small establishments are more volatile because of the lower marginal labour productivity. Small establishments have less fixed costs associated with hiring labour and, therefore, adjust more quickly. They also tend to be less capital intensive and, therefore, rely more on increases in labour inputs than on increases in capital inputs. Small establishments also experience more entry and exit by plants that are relatively more labour intensive than incumbents in the same size class.

The long-run adjustment coefficients for growing small establishments are much lower than the short-run coefficients, thereby demonstrating that greater productivity growth emerges over the longer period in this group. Differences in these coefficients across size classes reflect differences in the contribution to overall productivity growth. The lower is the coefficient for those expanding output, the greater are labour productivity gains. It is, therefore, significant that there are smaller differences in the labour adjustment coefficients between small and mediumsized establishments in the long-run than the short-run for establishments expanding employment. The relative differences across size classes for the adjustment coefficients for contracting establishments are also smaller in the long-run as opposed to the short-run. These longer-run differences are more indicative of basic differences in production technologies-since they reflect the possibilities for longer-run substitution of labour for capital and the exploitation of economies of scale as establishments grow.

There are also substantial differences across major industry sectors in the volatility of labour markets. Some of this arises because of differences in short-run fixities. The sectors where employment growth responds most to short-run output increases are, not surprisingly, the labour intensive, natural resources, and product-differentiated industries where capital intensity is 
lower. It is somewhat more of a surprise that science-based industries also have very high response rates in the short-run-but then their capital intensity (as measured by plant and equipment) is also relatively low. Labour intensive, natural resources and product-differentiated industries also have large response rates for contracting establishments.

In the long-run, the labour intensive, product-differentiated and natural-resource industries still have the largest adjustment coefficients, at least for small establishments. These sectors also have the greatest reductions for contracting establishments. While some establishments in these sectors are growing and their productivity is not increasing at the rate seen in other industries (because of capital intensity differences), other establishments are restructuring and dramatically increasing their productivity in these industries. Earlier results (Baldwin and Rafiquzzaman, 1994) show that these sectors have been going through more restructuring than others.

The food and beverage sector's short-run response is somewhat less than the response in labour and natural resource industries, whether we examine job expansion or job contraction. But these short-run coefficients are more indicative of the short-run volatility of labour markets. In the long-run, food and beverages experiences a mixed performance relative to other sectors. Their adjustment coefficients for expanding plants of all sizes are lower than the corresponding coefficients in all other sectors-thereby indicating greater marginal productivity. For contracting establishments, the coefficients are also smaller. For contracting establishments, this indicates smaller productivity gains. Thus, where the food and beverage industry has been expanding, it has been taking advantage of new technologies to improve its labour productivity. Where markets are mature and there is some contraction in sales, less restructuring has been taking place than in other sectors.

Foreign establishments in most of the constituent sectors and, for the manufacturing sector as a whole, create and eliminate fewer jobs in response to output changes than their Canadian counterparts. In the short-run, then, labour markets in which foreign establishments operate are less volatile. Indeed, the coefficient for growing large foreign establishments suggests virtually no change in employment for changes in output. In the longer run, the smaller coefficient for foreign-controlled establishments that are expanding employment indicates that this group has the highest marginal labour productivity. On the other hand, for contracting establishments, foreign-control brings about less labour adjustment. This suggests that restructuring, which dominates the contracting group in general, has not been as important a source of productivity growth for foreign-owned establishments.

For the food and beverage sector, there is no significant difference in job creation between the domestic- and foreign-controlled establishments in the short-run, while there is for most other sectors. There is for contracting plants. In the long-run, however, there are significant differences in the marginal productivity ratios of foreign-controlled establishments in the food and beverage sector for both growing and contracting plants.

The effect of differences in marginal labour adjustments is translated into differences in the pattern of increases in average labour productivity. Average labour productivity has increased more over time for contracting plants than for growing plants, for large as opposed to small plants and for foreign as opposed to domestic plants. Restructuring that has seen the decline in 
the importance (in terms of share of employment) of large plants and a decline in the importance of foreign-controlled plants (in terms of share of employment) would have slowed productivity growth.

It is noteworthy that it is not only a shift in employment that has caused this decline. The differences between small and large establishments and domestic and foreign plants have increased over the period of the study. Whether this is caused by a change in technology, changing relative capital intensity, improvements in efficiency, or is ascribed to some other factor was not addressed in this study. We do know that foreign and domestic plants differ in terms of their application of new advanced computer based technologies (Baldwin, Rama and Sabourin, 1999). We also know that variables like average wage rates have been going up in those plants employing these technologies relative to those not employing these technologies (Baldwin, Gray and Johnson, 1996a; Baldwin and Rafiquzzaman, 1998). The changes in average labour productivity that we have outlined in this study may just reflect these technological differences. This is a topic for additional research.

It is also evident that these changes take place slowly. The trends in relative labour productivity, whether they be in terms of differences across size-classes or differences across nationality groups have developed slowly-but there is little doubt about the direction of the trend. 
Table 2. Mean Values* for Job Creation, Job Elimination and Output Changes, 1973-93

\begin{tabular}{|l|r|r|r|r|r|r|}
\hline & \multicolumn{3}{|c|}{ SHORT-RUN } & \multicolumn{3}{c|}{ LONG-RUN } \\
\cline { 2 - 7 } \multicolumn{1}{c|}{ SECTOR } & $\begin{array}{c}\text { JOB } \\
\text { CHANGE } \\
\text { Number }\end{array}$ & $\begin{array}{c}\text { OUTPUT } \\
\text { CHANGE } \\
\text { (\$ Million) }\end{array}$ & $\begin{array}{c}\text { TURNOVER } \\
\text { RATE }\end{array}$ & $\begin{array}{c}\text { JOB } \\
\text { CHANGE } \\
\text { Number }\end{array}$ & $\begin{array}{c}\text { OUTPUT } \\
\text { CHANGE } \\
\text { (\$ Million) }\end{array}$ & $\begin{array}{c}\text { TURNOVER } \\
\text { RATE }\end{array}$ \\
\hline JOB CREATION & & & & & & \\
Food \& Beverage & 3,672 & 415 & 8.8 & 6,386 & 1,145 & 5.6 \\
Natural-resources & 5,511 & 435 & 12.7 & 8,212 & 1,026 & 8.0 \\
Labour-intensive & 7,406 & 413 & 17.9 & 10,746 & 884 & 12.2 \\
Scale-based & 8,210 & 1,203 & 6.8 & 13,489 & 2,750 & 4.9 \\
Product-differentiated & 4,630 & 380 & 12.2 & 6,825 & 784 & 8.7 \\
Science-based & 3,417 & 307 & 11.1 & 6,413 & 941 & 6.8 \\
All Sectors & 5,474 & 526 & 10.4 & 8,679 & 1,255 & 6.9 \\
& & & & & & \\
JOB CONTRACTION & & & & & & \\
Food \& Beverage & $-3,721$ & -319 & 11.7 & $-9,067$ & $-1,073$ & \\
Natural-resources & $-5,329$ & -335 & 15.9 & $-12,230$ & $-1,069$ & 11.4 \\
Labour-intensive & $-8,241$ & -388 & 21.2 & $-20,727$ & $-1,178$ & 17.6 \\
Scale-based & $-8,426$ & -729 & 11.6 & $-20,217$ & $-1,646$ & 12.3 \\
Product-differentiated & $-4,706$ & -304 & 15.5 & $-11,237$ & -793 & 14.2 \\
Science-based & $-3,246$ & -165 & 19.7 & $-7,255$ & -430 & 16.9 \\
All Sectors & $-5,612$ & -373 & 15.0 & $-13,456$ & $-1,032$ & 13.0 \\
\hline
\end{tabular}

* Mean values are the average of the 6 establishment categories' data over the length of the time period. 
Table 3. Short-Run and Long-Run Responses of Job Creation to Output Expansion, 1973-1993

\begin{tabular}{|c|c|c|c|c|c|c|}
\hline SECTOR & $\begin{array}{c}\text { SMALL } \\
\text { CANADIAN }\end{array}$ & $\begin{array}{l}\text { DUMMY } \\
\text { MEDIUM }\end{array}$ & $\begin{array}{c}\text { DUMMY } \\
\text { LARGE }\end{array}$ & $\begin{array}{l}\text { DUMMY } \\
\text { FOREIGN }\end{array}$ & $\begin{array}{l}\text { DUMMY } \\
\text { FB }\end{array}$ & $\mathbf{R}^{2}$ \\
\hline \multicolumn{7}{|l|}{ Short-Run } \\
\hline Food \& Beverage & $\begin{array}{r}7,196 \\
(547)^{* * *}\end{array}$ & $\begin{array}{r}-6,539 \\
(631)^{* * *}\end{array}$ & $\begin{array}{r}-6,793 \\
(629)^{* * *}\end{array}$ & $\begin{array}{r}-155 \\
(-518)\end{array}$ & & 0.90 \\
\hline Natural-resources & $\begin{array}{r}12,550 \\
(888)^{* * *}\end{array}$ & $\begin{array}{r}-9,276 \\
(906)^{* * *}\end{array}$ & $\begin{array}{r}-9,550 \\
(954)^{* * *}\end{array}$ & $\begin{array}{r}-2,777 \\
(441)^{* * * *}\end{array}$ & & 0.79 \\
\hline Labour-intensive & $\begin{array}{r}14,370 \\
(913)^{* * *}\end{array}$ & $\begin{array}{r}-11,530 \\
(917)^{* * *}\end{array}$ & $\begin{array}{r}-9,176 \\
(1,256)^{* * *}\end{array}$ & $\begin{array}{r}-4,103 \\
(786)^{* * *}\end{array}$ & & 0.90 \\
\hline Scale-based & $\begin{array}{r}4,907 \\
(599) * * *\end{array}$ & $\begin{array}{r}-1,438 \\
(559)^{* *}\end{array}$ & $\begin{array}{r}-1,471 \\
(513)^{* * *}\end{array}$ & $\begin{array}{r}-3,263 \\
(471)^{* * * *}\end{array}$ & & 0.73 \\
\hline Product-differentiated & $\begin{array}{r}13,622 \\
(1,131)^{* * *}\end{array}$ & $\begin{array}{r}-7,900 \\
(1,359)^{* * *}\end{array}$ & $\begin{array}{r}-7,434 \\
(1,353)^{* * *}\end{array}$ & $\begin{array}{r}-5,919 \\
(891)^{* * * *}\end{array}$ & & 0.71 \\
\hline Science-based & $\begin{array}{r}11,811 \\
(1157)^{* * *}\end{array}$ & $\begin{array}{r}-7,746 \\
(1,386)^{* * *}\end{array}$ & $\begin{array}{r}-9,446 \\
(1,304)^{* * *}\end{array}$ & $\begin{array}{l}-1,196 \\
(715)^{*}\end{array}$ & & 0.81 \\
\hline All Sectors & $\begin{array}{r}9,849 \\
(118)^{* * *}\end{array}$ & $\begin{array}{r}-5,201 \\
(92)^{* * *}\end{array}$ & $\begin{array}{r}-4,910 \\
(96) * * *\end{array}$ & $\begin{array}{r}-4,705 \\
(85)^{* * *}\end{array}$ & $\begin{array}{r}-3,407 \\
(107)^{* * *}\end{array}$ & 0.98 \\
\hline \multicolumn{7}{|l|}{ Long-Run } \\
\hline Food \& Beverage & $\begin{array}{r}4,787 \\
(596) * * *\end{array}$ & $\begin{array}{r}-3,022 \\
(641)^{* * *}\end{array}$ & $\begin{array}{r}-3,601 \\
(624)^{* * *}\end{array}$ & $\begin{array}{r}-2101 \\
(470)^{* * *}\end{array}$ & & 0.72 \\
\hline Natural-resources & $\begin{array}{r}8,454 \\
(608) * * *\end{array}$ & $\begin{array}{r}-4,775 \\
(657)^{* * *}\end{array}$ & $\begin{array}{r}-5,181 \\
(675)^{* * *}\end{array}$ & $\begin{array}{r}-3,258 \\
(605)^{* * *}\end{array}$ & & 0.86 \\
\hline Labour-intensive & $\begin{array}{r}10,879 \\
(792)^{* * *}\end{array}$ & $\begin{array}{r}-7,698 \\
(970)^{* * *}\end{array}$ & $\begin{array}{r}-9,096 \\
(1,112)^{* * *}\end{array}$ & $\begin{array}{r}-780 \\
(-825)\end{array}$ & & 0.92 \\
\hline Scale-based & $\begin{array}{r}976 \\
(581)^{*}\end{array}$ & $\begin{array}{r}1,978 \\
(541)^{* * *}\end{array}$ & $\begin{array}{r}166 \\
(308)\end{array}$ & $\begin{array}{r}-653 \\
(541)\end{array}$ & & 0.35 \\
\hline Product-differentiated & $\begin{array}{r}10,000 \\
(661)^{* * * *}\end{array}$ & $\begin{array}{r}-3,663 \\
(943)^{* * *}\end{array}$ & $\begin{array}{r}-4,374 \\
(940)^{* * *}\end{array}$ & $\begin{array}{r}-5,278 \\
(799)^{* * * *}\end{array}$ & & 0.88 \\
\hline Science-based & $\begin{array}{r}8,291 \\
(971)^{* * * *}\end{array}$ & $\begin{array}{r}-4,215 \\
(1,166)^{* * *}\end{array}$ & $\begin{array}{r}-4,780 \\
(1,248)^{* * *}\end{array}$ & $\begin{array}{r}-1,866 \\
(670)^{* * * *}\end{array}$ & & 0.79 \\
\hline All Sectors & $\begin{array}{r}6,723 \\
(218)^{* * * *}\end{array}$ & $\begin{array}{r}-2,388 \\
(143)^{* * * *}\end{array}$ & $\begin{array}{r}-2,262 \\
(160)^{* * *}\end{array}$ & $\begin{array}{r}-3,928 \\
(160)^{* * * *}\end{array}$ & $\begin{array}{r}-2,596 \\
(143)^{* * *}\end{array}$ & 0.92 \\
\hline
\end{tabular}

Figures in parentheses are the standard errors.

Three asterisks $(* * *)$, two asterisks $(* *)$ and one asterisk $(*)$ respectively denote the significance of the coefficient at $99 \%$, $95 \%$ and $90 \%$ level.

The job changes are measured in number of employees, while the output changes are measured in billions of dollars. 
Table 4. Short-Run and Long-Run Responses of Job Creation to Output Expansion, 1973-1993

\begin{tabular}{|c|c|c|c|c|c|c|}
\hline SECTOR & $\begin{array}{c}\text { SMALL } \\
\text { CANADIAN }\end{array}$ & MEDIUM & LARGE & FOREIGN & FB & $\mathbf{R}^{2}$ \\
\hline \multicolumn{7}{|l|}{ Short-Run } \\
\hline Food \& Beverage & $\begin{array}{r}7,196 \\
(547)^{* * *}\end{array}$ & $\begin{array}{r}657 \\
(501)\end{array}$ & $\begin{array}{r}403 \\
(552)\end{array}$ & $\begin{array}{r}7,041 \\
(546)^{* * * *}\end{array}$ & & 0.90 \\
\hline Natural-resources & $\begin{array}{r}12,550 \\
(888)^{* * * *}\end{array}$ & $\begin{array}{r}3,274 \\
(402)^{* * *}\end{array}$ & $\begin{array}{r}3,000 \\
(564)^{* * *}\end{array}$ & $\begin{array}{r}9,773 \\
(903)^{* * * *}\end{array}$ & & 0.79 \\
\hline Labour-intensive & $\begin{array}{r}14,370 \\
(913)^{* * * *}\end{array}$ & $\begin{array}{r}2,840 \\
(496)^{* * * *}\end{array}$ & $\begin{array}{r}5,194 \\
(1,019)^{* * *}\end{array}$ & $\begin{array}{r}10,267 \\
(956)^{* * * *}\end{array}$ & & 0.90 \\
\hline Scale-based & $\begin{array}{r}4,907 \\
(599) * * *\end{array}$ & $\begin{array}{r}3,469 \\
(522)^{* * * *}\end{array}$ & $\begin{array}{r}3,436 \\
(475)^{* * * *}\end{array}$ & $\begin{array}{r}1,644 \\
(485)^{* * *}\end{array}$ & & 0.73 \\
\hline Product-differentiated & $\begin{array}{r}13,622 \\
(1,131)^{* * *}\end{array}$ & $\begin{array}{r}5,722 \\
(863)^{* * *}\end{array}$ & $\begin{array}{r}6,188 \\
(950)^{* * * *}\end{array}$ & $\begin{array}{r}7,703 \\
(1,239)^{* * *}\end{array}$ & & 0.71 \\
\hline Science-based & $\begin{array}{r}11,811 \\
(1,157)^{* * *}\end{array}$ & $\begin{array}{r}4,065 \\
(824) * * *\end{array}$ & $\begin{array}{r}2,365 \\
(737)^{* * * *}\end{array}$ & $\begin{array}{r}10,615 \\
(1,239)^{* * *}\end{array}$ & & 0.81 \\
\hline All Sectors & $\begin{array}{r}9,849 \\
(118)^{* * * *}\end{array}$ & $\begin{array}{r}4,648 \\
(85)^{* * *}\end{array}$ & $\begin{array}{r}4,939 \\
(102)^{* * * *}\end{array}$ & $\begin{array}{r}5,144 \\
(90)^{* * * *}\end{array}$ & $\begin{array}{r}6,607 \\
(104)^{* * *}\end{array}$ & 0.98 \\
\hline \multicolumn{7}{|l|}{ Long-Run } \\
\hline Food \& Beverage & $\begin{array}{r}4,787 \\
(596)^{* * *}\end{array}$ & $\begin{array}{r}1,765 \\
(338)^{* * *}\end{array}$ & $\begin{array}{r}1,186 \\
(532)^{* * *}\end{array}$ & $\begin{array}{r}2,686 \\
(583)^{* * * *}\end{array}$ & & 0.72 \\
\hline Natural-resources & $\begin{array}{r}8,454 \\
(608)^{* * *}\end{array}$ & $\begin{array}{r}3,679 \\
(554) * * *\end{array}$ & $\begin{array}{r}3,273 \\
(628)^{* * *}\end{array}$ & $\begin{array}{r}5,196 \\
(622)^{* * *}\end{array}$ & & 0.86 \\
\hline Labour-intensive & $\begin{array}{r}10,879 \\
(792)^{* * *}\end{array}$ & $\begin{array}{r}3,181 \\
(608)^{* * * *}\end{array}$ & $\begin{array}{r}1,783 \\
(760)^{* * * *}\end{array}$ & $\begin{array}{r}10,099 \\
(1,102)^{* * *}\end{array}$ & & 0.92 \\
\hline Scale-based & $\begin{array}{r}976 \\
(581)^{*}\end{array}$ & $\begin{array}{r}2,954 \\
(682)^{* * *}\end{array}$ & $\begin{array}{r}1,142 \\
(549)^{*}\end{array}$ & $\begin{array}{r}323 \\
(272)\end{array}$ & & 0.35 \\
\hline Product-differentiated & $\begin{array}{r}10,000 \\
(661)^{* * *}\end{array}$ & $\begin{array}{r}6,337 \\
(856)^{* * *}\end{array}$ & $\begin{array}{r}5,626 \\
(847)^{* * *}\end{array}$ & $\begin{array}{r}4,722 \\
(884)^{* * * *}\end{array}$ & & 0.88 \\
\hline Science-based & $\begin{array}{r}8,291 \\
(971)^{* * *}\end{array}$ & $\begin{array}{r}4,076 \\
(737)^{* * *}\end{array}$ & $\begin{array}{r}3,511 \\
(731)^{* * *}\end{array}$ & $\begin{array}{r}6,425 \\
(1,181)^{* * *}\end{array}$ & & 0.79 \\
\hline All Sectors & $\begin{array}{r}6,723 \\
(218)^{* * *}\end{array}$ & $\begin{array}{r}4,335 \\
(146)^{* * *}\end{array}$ & $\begin{array}{r}4,461 \\
(167)^{* * * *}\end{array}$ & $\begin{array}{r}2,795 \\
(128)^{* * * *}\end{array}$ & $\begin{array}{r}4,111 \\
(143)^{* * *}\end{array}$ & 0.92 \\
\hline
\end{tabular}

Figures in parentheses are the standard errors.

Three asterisks $(* * *)$, two asterisks $(* *)$ and one asterisk $(*)$ respectively denote the significance of the coefficient at $99 \%, 95 \%$ and $90 \%$ level.

The job changes are measured in number of employees, while the output changes are measured in billions of dollars. 
Table 5. Short-Run and Long-Run Responses of Job Elimination to Output Contraction, 1973-1993

\begin{tabular}{|c|c|c|c|c|c|c|}
\hline SECTOR & $\begin{array}{c}\text { SMALL } \\
\text { CANADIAN }\end{array}$ & $\begin{array}{l}\text { DUMMY } \\
\text { MEDIUM }\end{array}$ & $\begin{array}{c}\text { DUMMY } \\
\text { LARGE }\end{array}$ & $\begin{array}{c}\text { DUMMY } \\
\text { FOREIGN }\end{array}$ & $\begin{array}{c}\text { DUMMY } \\
\text { FB }\end{array}$ & $\mathbf{R}^{2}$ \\
\hline \multicolumn{7}{|l|}{ Short-Run } \\
\hline Food \& Beverage & $\begin{array}{r}7,274 \\
(553)^{* * *}\end{array}$ & $\begin{array}{r}-3,507 \\
(604)^{* *}\end{array}$ & $\begin{array}{r}-3,421 \\
(678)^{* * *}\end{array}$ & $\begin{array}{r}1,368 \\
(574)^{* *}\end{array}$ & & 0.91 \\
\hline Natural-resources & $\begin{array}{r}12,836 \\
(1,051)^{* * * *}\end{array}$ & $\begin{array}{r}-8,558 \\
(1,263)^{* * *}\end{array}$ & $\begin{array}{r}-9,280 \\
(1,246)^{* * *}\end{array}$ & $\begin{array}{r}-2,993 \\
(617)^{* * * *}\end{array}$ & & 0.84 \\
\hline Labour-intensive & $\begin{array}{r}13,314 \\
(828)^{* * *}\end{array}$ & $\begin{array}{r}-7,896 \\
(1,285)^{* * *}\end{array}$ & $\begin{array}{r}-6,364 \\
(1,199)^{* * * *}\end{array}$ & $\begin{array}{r}-2,423 \\
(835)^{* * * *}\end{array}$ & & 0.92 \\
\hline Scale-based & $\begin{array}{r}3,721 \\
(739)^{* * * *}\end{array}$ & $\begin{array}{r}2,569 \\
(790)^{* *}\end{array}$ & $\begin{array}{r}-697 \\
(710)\end{array}$ & $\begin{array}{c}-1,068 \\
(433)^{* *}\end{array}$ & & 0.78 \\
\hline Product-differentiated & $\begin{array}{r}13,792 \\
(1,108) * * *\end{array}$ & $\begin{array}{r}-4,669 \\
(1,214)^{* * *}\end{array}$ & $\begin{array}{r}-6,265 \\
(1,190)^{* * * *}\end{array}$ & $\begin{array}{r}-3,663 \\
(797)^{* * *}\end{array}$ & & 0.85 \\
\hline Science-based & $\begin{array}{r}5,931 \\
(846)^{* * *}\end{array}$ & $\begin{array}{r}-876 \\
(782)\end{array}$ & $\begin{array}{r}1,928 \\
(879)^{* *}\end{array}$ & $\begin{array}{l}-1,376 \\
(768)^{*}\end{array}$ & & 0.85 \\
\hline All Sectors & $\begin{array}{r}10,422 \\
(167)^{* * *}\end{array}$ & $\begin{array}{r}-5,234 \\
(205)^{* * *}\end{array}$ & $\begin{array}{r}-6,929 \\
(194)^{* * *}\end{array}$ & $\begin{array}{r}-1,579 \\
(115)^{* * *}\end{array}$ & $\begin{array}{r}-2,529 \\
(119)^{* * *}\end{array}$ & 0.98 \\
\hline \multicolumn{7}{|l|}{ Long-Run } \\
\hline Food \& Beverage & $\begin{array}{r}4,511 \\
(558)^{* * * *}\end{array}$ & $\begin{array}{r}-707 \\
(470)\end{array}$ & $\begin{array}{r}-643 \\
(620)\end{array}$ & $\begin{array}{r}-1,723 \\
(562)^{* * *}\end{array}$ & & 0.89 \\
\hline Natural-resources & $\begin{array}{r}10,633 \\
(773)^{* * * *}\end{array}$ & $\begin{array}{r}-5,695 \\
(950)^{* * * *}\end{array}$ & $\begin{array}{r}-6,334 \\
(997) * * *\end{array}$ & $\begin{array}{r}-3,558 \\
(484)^{* * * *}\end{array}$ & & 0.92 \\
\hline Labour-intensive & $\begin{array}{r}12,604 \\
(787)^{* * * *}\end{array}$ & $\begin{array}{r}-5,970 \\
(1,360)^{* * * *}\end{array}$ & $\begin{array}{r}-7,511 \\
(1,358)^{* * *}\end{array}$ & $\begin{array}{r}-1,282 \\
(1,180)\end{array}$ & & 0.97 \\
\hline Scale-based & $\begin{array}{r}8,070 \\
(788)^{* * * *}\end{array}$ & $\begin{array}{r}633 \\
(892)\end{array}$ & $\begin{array}{r}-2,429 \\
(785)^{* * * *}\end{array}$ & $\begin{array}{r}-3,669 \\
(411)^{* * * *}\end{array}$ & & 0.82 \\
\hline Product-differentiated & $\begin{array}{r}13,124 \\
(925)^{* * * *}\end{array}$ & $\begin{array}{r}-4,005 \\
(1,078)^{* * *}\end{array}$ & $\begin{array}{r}-3,835 \\
(964)^{* * *}\end{array}$ & $\begin{array}{r}-5,100 \\
(703)^{* * * *}\end{array}$ & & 0.89 \\
\hline Science-based & $\begin{array}{r}7,432 \\
(1,050)^{* * *}\end{array}$ & $\begin{array}{r}-740 \\
(1,045)\end{array}$ & $\begin{array}{r}5,396 \\
(1,318)^{* * *}\end{array}$ & $\begin{array}{r}-2,977 \\
(1,035)^{* * *}\end{array}$ & & 0.84 \\
\hline All Sectors & $\begin{array}{r}10,932 \\
(214)^{* * *}\end{array}$ & $\begin{array}{r}-3,761 \\
(228)^{* * *}\end{array}$ & $\begin{array}{r}-5,221 \\
(269)^{* * *}\end{array}$ & $\begin{array}{r}-3,765 \\
(144)^{* * *}\end{array}$ & $\begin{array}{r}-3,764 \\
(170)^{* * * *}\end{array}$ & 0.98 \\
\hline
\end{tabular}

Figures in parentheses are the standard errors.

Three asterisks $(* * *)$, two asterisks $(* *)$ and one asterisk $(*)$ respectively denote the significance of the coefficient at 99\%, $95 \%$ and $90 \%$ level.

The job changes are measured in number of employees, while the output changes are measured in billions of dollars. 
Table 6. Short-Run and Long-Run Responses of Job Elimination to Output Contraction, 1973-1993

\begin{tabular}{|c|c|c|c|c|c|c|}
\hline SECTOR & $\begin{array}{c}\text { SMALL } \\
\text { CANADIAN }\end{array}$ & MEDIUM & LARGE & FOREIGN & FB & $\mathbf{R}^{2}$ \\
\hline \multicolumn{7}{|l|}{ Short-Run } \\
\hline Food \& Beverage & $\begin{array}{r}7,274 \\
(553)^{* * *}\end{array}$ & $\begin{array}{r}3,767 \\
(479)^{* * * *}\end{array}$ & $\begin{array}{r}3,853 \\
(501)^{* * *}\end{array}$ & $\begin{array}{r}8,642 \\
(681)^{* * * *}\end{array}$ & & 0.91 \\
\hline Natural-resources & $\begin{array}{r}12,836 \\
(1,051)^{* * *}\end{array}$ & $\begin{array}{r}4,278 \\
(688)^{* * * *}\end{array}$ & $\begin{array}{r}3,556 \\
(636)^{* * * *}\end{array}$ & $\begin{array}{r}9,843 \\
(1,227)^{* * *}\end{array}$ & & 0.84 \\
\hline Labour-intensive & $\begin{array}{r}13,314 \\
(828)^{* * *}\end{array}$ & $\begin{array}{r}5,418 \\
(937)^{* * * *}\end{array}$ & $\begin{array}{r}6,950 \\
(966)^{* * * *}\end{array}$ & $\begin{array}{r}10,891 \\
(1,124)^{* * *}\end{array}$ & & 0.92 \\
\hline Scale-based & $\begin{array}{r}3,721 \\
(739)^{* * * *}\end{array}$ & $\begin{array}{r}6,290 \\
(492)^{* * * *}\end{array}$ & $\begin{array}{r}3,024 \\
(418)^{* * * *}\end{array}$ & $\begin{array}{r}2,653 \\
(645)^{* * * *}\end{array}$ & & 0.78 \\
\hline Product-differentiated & $\begin{array}{r}13,792 \\
(1,108)^{* * *}\end{array}$ & $\begin{array}{r}9,123 \\
(865)^{* * * *}\end{array}$ & $\begin{array}{r}7,527 \\
(785)^{* * * *}\end{array}$ & $\begin{array}{r}10,129 \\
(1,084)^{* * *}\end{array}$ & & 0.85 \\
\hline Science-based & $\begin{array}{r}5,931 \\
(846)^{* * * *}\end{array}$ & $\begin{array}{r}5,055 \\
(765)^{* * *}\end{array}$ & $\begin{array}{r}7,859 \\
(790)^{* * * *}\end{array}$ & $\begin{array}{r}5,930 \\
(759)^{* * * *}\end{array}$ & & 0.85 \\
\hline All Sectors & $\begin{array}{r}10,422 \\
(167)^{* * * *}\end{array}$ & $\begin{array}{r}5,188 \\
(119)^{* * * *}\end{array}$ & $\begin{array}{r}3,493 \\
(130)^{* * * *}\end{array}$ & $\begin{array}{r}8,843 \\
(185)^{* * * *}\end{array}$ & $\begin{array}{r}7,893 \\
(198) * * *\end{array}$ & 0.98 \\
\hline \multicolumn{7}{|l|}{ Long-Run } \\
\hline Food \& Beverage & $\begin{array}{r}4,511 \\
(558)^{* * * *}\end{array}$ & $\begin{array}{r}3,804 \\
(225)^{* * * *}\end{array}$ & $\begin{array}{r}3,868 \\
(517)^{* * * *}\end{array}$ & $\begin{array}{r}2,788 \\
(627)^{* * * *}\end{array}$ & & 0.89 \\
\hline Natural-resources & $\begin{array}{r}10,633 \\
(773)^{* * *}\end{array}$ & $\begin{array}{r}4,938 \\
(514)^{* * * *}\end{array}$ & $\begin{array}{r}4,299 \\
(584)^{* * * *}\end{array}$ & $\begin{array}{r}7,075 \\
(937)^{* * *}\end{array}$ & & 0.92 \\
\hline Labour-intensive & $\begin{array}{r}12,604 \\
(787)^{* * * *}\end{array}$ & $\begin{array}{r}6,634 \\
(1,210)^{* * * *}\end{array}$ & $\begin{array}{r}5,093 \\
(1,085)^{* * *}\end{array}$ & $\begin{array}{r}11,322 \\
(1,364)^{* * *}\end{array}$ & & 0.97 \\
\hline Scale-based & $\begin{array}{r}8,070 \\
(788)^{* * *}\end{array}$ & $\begin{array}{r}8,703 \\
(743)^{* * * *}\end{array}$ & $\begin{array}{r}5,641 \\
(493)^{* * *}\end{array}$ & $\begin{array}{r}4,401 \\
(767)^{* * *}\end{array}$ & & 0.82 \\
\hline Product-differentiated & $\begin{array}{r}13,124 \\
(925)^{* * * *}\end{array}$ & $\begin{array}{r}9,119 \\
(667)^{* * *}\end{array}$ & $\begin{array}{r}9,289 \\
(740)^{* * *}\end{array}$ & $\begin{array}{r}8,024 \\
(966)^{* * *}\end{array}$ & & 0.89 \\
\hline Science-based & $\begin{array}{r}7,432 \\
(1,050)^{* * *}\end{array}$ & $\begin{array}{r}6,692 \\
(1,036)^{* * *}\end{array}$ & $\begin{array}{r}12,828 \\
(1,295)^{* * *}\end{array}$ & $\begin{array}{r}4,455 \\
(1,091)^{* * *}\end{array}$ & & 0.84 \\
\hline All Sectors & $\begin{array}{r}10,932 \\
(214)^{* * *}\end{array}$ & $\begin{array}{r}7,171 \\
(180)^{* * *}\end{array}$ & $\begin{array}{r}5,711 \\
(197)^{* * * *}\end{array}$ & $\begin{array}{r}7,167 \\
(246)^{* * *}\end{array}$ & $\begin{array}{r}7,168 \\
(206)^{* * *}\end{array}$ & 0.98 \\
\hline
\end{tabular}

Figures in parentheses are the standard errors.

Three asterisks $(* * *)$, two asterisks $(* *)$ and one asterisk $(*)$ respectively denote the significance of the coefficient at $99 \%, 95 \%$ or $90 \%$ level.

The job changes are measured in number of employees, while the output changes are measured in billions of dollars. 
Table 7. Effect of Marginal Changes in Employment and Output on Average Labour Productivity in the Canadian Food and Beverage Sector

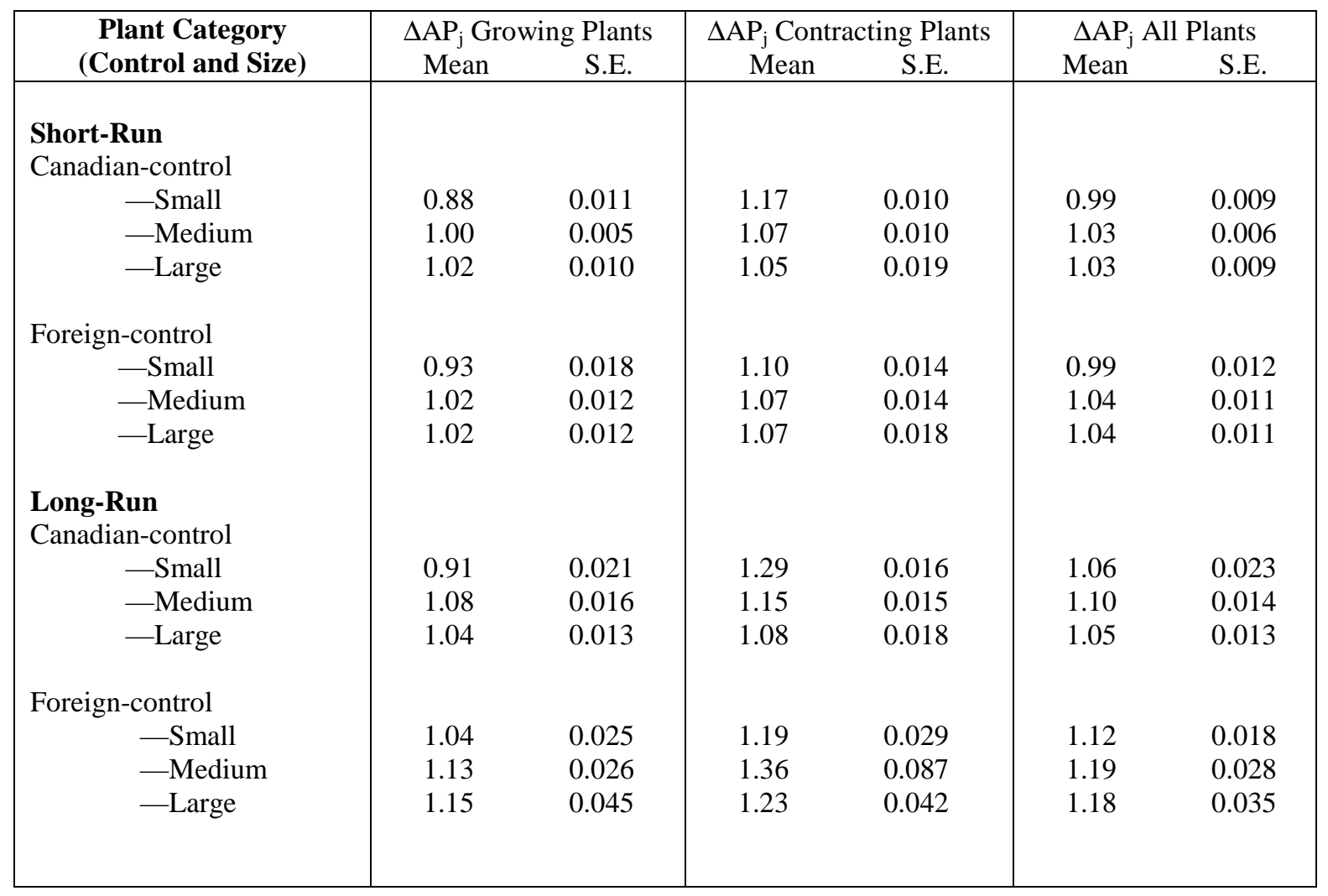


Table 8. Effect of Marginal Changes in Employment and Output on Average Labour Productivity in the Canadian Manufacturing Sector Excluding Food and Beverage Industries

\begin{tabular}{|c|c|c|c|c|c|c|}
\hline Plant Category & $\Delta \mathrm{AP}_{\mathrm{i}} \mathrm{Gr}_{\mathrm{l}}$ & ig Plants & $\Delta \mathrm{AP}_{\mathrm{i}} \mathrm{Col}$ & ng Plants & $\Delta \mathrm{AP}_{\mathrm{i}}$ & Plants \\
\hline (Control and size) & Mean & S.E. & Mean & S.E. & Mean & S.E. \\
\hline Short-Run & & & & & & \\
\hline Canadian-control & & & & & & \\
\hline - Small & 0.91 & 0.006 & 1.17 & 0.008 & 1.01 & 0.005 \\
\hline - Medium & 1.01 & 0.006 & 1.08 & 0.009 & 1.04 & 0.006 \\
\hline - Large & 1.04 & 0.007 & 1.05 & 0.010 & 1.04 & 0.007 \\
\hline Foreign-control & & & & & & \\
\hline - Small & 0.94 & 0.019 & 1.10 & 0.009 & 1.01 & 0.011 \\
\hline - Medium & 1.01 & 0.011 & 1.08 & 0.008 & 1.04 & 0.006 \\
\hline - Large & 1.02 & 0.010 & 1.09 & 0.017 & 1.05 & 0.007 \\
\hline Long-Run & & & & & & \\
\hline Canadian-control & & & & & & \\
\hline - Small & 0.98 & 0.009 & 1.28 & 0.014 & 1.11 & 0.008 \\
\hline - Medium & 1.11 & 0.013 & 1.22 & 0.024 & 1.16 & 0.011 \\
\hline - Large & 1.19 & 0.015 & 1.22 & 0.027 & 1.17 & 0.015 \\
\hline Foreign-control & & & & & & \\
\hline - Small & 1.04 & 0.025 & 1.22 & 0.018 & 1.14 & 0.023 \\
\hline - Medium & 1.11 & 0.012 & 1.24 & 0.017 & 1.17 & 0.011 \\
\hline - Large & 1.18 & 0.024 & 1.33 & 0.040 & 1.22 & 0.020 \\
\hline
\end{tabular}


Table 9. Impacts of Size and Control on Changes in Average Labour Productivity, Canadian Food and Beverage Sector

\begin{tabular}{|c|c|c|c|c|c|c|}
\hline \multirow{2}{*}{$\begin{array}{c}\text { Explanatory } \\
\text { Variable }\end{array}$} & \multicolumn{3}{|c|}{ Short-Run } & \multicolumn{3}{|c|}{ Long-Run } \\
\hline & $\begin{array}{l}\text { Growing } \\
\text { Plants }\end{array}$ & $\begin{array}{c}\text { Contracting } \\
\text { Plants }\end{array}$ & All Plants & $\begin{array}{l}\text { Growing } \\
\text { Plants }\end{array}$ & $\begin{array}{c}\text { Contracting } \\
\text { Plants }\end{array}$ & All Plants \\
\hline Intercept & $\begin{array}{l}0.94 \\
(0.019) * * *\end{array}$ & $\begin{array}{l}1.14 \\
(0.024) * * *\end{array}$ & $\begin{array}{l}1.024 \\
(0.015)^{* * *}\end{array}$ & $\begin{array}{l}1.034 \\
(0.036)^{* * *}\end{array}$ & $\begin{array}{l}1.25 \\
(0.070) * * *\end{array}$ & $\begin{array}{c}1.162 \\
(0.031)^{* * *}\end{array}$ \\
\hline Trend & $\begin{array}{l}-0.0055 \\
(0.002)^{* * *}\end{array}$ & $\begin{array}{l}0.0003 \\
(0.0022)\end{array}$ & $\begin{array}{l}-0.0036 \\
(0.0013) * * *\end{array}$ & $\begin{array}{l}-0.0147 \\
(0.004)^{* * *}\end{array}$ & $\begin{array}{l}-0.0078 \\
(0.0079)\end{array}$ & $\begin{array}{l}-0.017 \\
(0.0035)^{* * *}\end{array}$ \\
\hline $\mathrm{S}_{2}$ & $\begin{array}{l}0.0485 \\
(0.023)^{* *}\end{array}$ & $\begin{array}{l}-0.063 \\
(0.0293) * *\end{array}$ & $\begin{array}{l}-0.0014 \\
(0.083)\end{array}$ & $\begin{array}{l}0.074 \\
(0.045)^{*}\end{array}$ & $\begin{array}{l}-0.044 \\
(0.0856)\end{array}$ & $\begin{array}{r}-0.021 \\
(0.038) \\
\end{array}$ \\
\hline $\mathrm{S}_{3}$ & $\begin{array}{l}0.0543 \\
(0.023)^{* *}\end{array}$ & $\begin{array}{l}-0.092 \\
(0.0293) * * *\end{array}$ & $\begin{array}{l}-0.0057 \\
(0.083) \\
\end{array}$ & $\begin{array}{r}0.0003 \\
(0.045) \\
\end{array}$ & $\begin{array}{l}-0.121 \\
(0.0856)\end{array}$ & $\begin{array}{l}-0.104 \\
(0.038)^{* * *}\end{array}$ \\
\hline $\mathrm{CF}$ & $\begin{array}{l}0.0013 \\
(0.0185)\end{array}$ & $\begin{array}{l}-0.038 \\
(0.0239)\end{array}$ & $\begin{array}{l}-0.0078 \\
(0.015)\end{array}$ & $\begin{array}{l}-0.038 \\
(0.036)\end{array}$ & $\begin{array}{l}-0.046 \\
(0.070)\end{array}$ & $\begin{array}{l}-0.031 \\
(0.031)\end{array}$ \\
\hline $\mathrm{S}_{2} *$ Trend & $\begin{array}{l}0.0060 \\
(0.0020)^{* * *}\end{array}$ & $\begin{array}{l}-0.0002 \\
(0.0026)\end{array}$ & $\begin{array}{l}0.0043 \\
(0.002)^{* * *}\end{array}$ & $\begin{array}{r}0.0073 \\
(0.005)\end{array}$ & $\begin{array}{c}0.0077 \\
(0.0097)\end{array}$ & $\begin{array}{c}0.0104 \\
(0.004)^{* *}\end{array}$ \\
\hline $\mathrm{S}_{3} *$ Trend & $\begin{array}{l}0.0067 \\
(0.0020) * * *\end{array}$ & $\begin{array}{l}0.0014 \\
(0.0026)\end{array}$ & $\begin{array}{l}0.0047 \\
(0.002) * * *\end{array}$ & $\begin{array}{l}0.0155 \\
(0.005)^{* * *}\end{array}$ & $\begin{array}{c}0.0050 \\
(0.0097)\end{array}$ & $\begin{array}{l}0.0169 \\
(0.004)^{* * *}\end{array}$ \\
\hline CF*Trend & $\begin{array}{l}0.0014 \\
(0.002)\end{array}$ & $\begin{array}{l}0.0023 \\
(0.0022)\end{array}$ & $\begin{array}{l}0.0017 \\
(0.0013)\end{array}$ & $\begin{array}{l}0.018 \\
(0.004)^{* * *}\end{array}$ & $\begin{array}{l}0.0178 \\
(0.0079) * *\end{array}$ & $\begin{array}{l}0.0167 \\
(0.0035)^{* * *}\end{array}$ \\
\hline $\mathrm{R}^{2}$ & 0.53 & 0.20 & 0.20 & 0.48 & 0.11 & 0.43 \\
\hline
\end{tabular}

Note: Three asterisks (***), two asterisks (**) and one asterisk (*) represents the significance of the coefficient at $99 \%, 95 \%$ and $90 \%$ levels, respectively. 
Table 10. Impacts of Size and Control on Changes in Average Labour Productivity, Canadian Manufacturing Sector Excluding Food and Beverage Industries

\begin{tabular}{|c|c|c|c|c|c|c|}
\hline \multirow{2}{*}{$\begin{array}{c}\text { Explanatory } \\
\text { Variable }\end{array}$} & \multicolumn{3}{|c|}{ Short-Run } & \multicolumn{3}{|c|}{ Long-Run } \\
\hline & $\begin{array}{l}\text { Growing } \\
\text { Plants }\end{array}$ & $\begin{array}{c}\text { Contracting } \\
\text { Plants }\end{array}$ & All Plants & $\begin{array}{l}\text { Growing } \\
\text { Plants }\end{array}$ & $\begin{array}{c}\text { Contracting } \\
\text { Plants }\end{array}$ & All Plants \\
\hline Intercept & $\begin{array}{c}0.962 \\
(0.017)^{* * *}\end{array}$ & $\begin{array}{l}1.12 \\
(0.017) * * *\end{array}$ & $\begin{array}{c}1.017 \\
(0.011)^{* * *}\end{array}$ & $\begin{array}{l}1.04 \\
(0.027)^{* * * *}\end{array}$ & $\begin{array}{c}1.231 \\
(0.039) * * *\end{array}$ & $\begin{array}{c}1.136 \\
(0.024) * * *\end{array}$ \\
\hline Trend & $\begin{array}{l}-0.0039 \\
(0.0016)^{* *}\end{array}$ & $\begin{array}{c}0.0024 \\
(0.0015)\end{array}$ & $\begin{array}{l}-0.0007 \\
(0.0010)\end{array}$ & $\begin{array}{l}-0.0067 \\
(0.0031)^{* *}\end{array}$ & $\begin{array}{l}0.0008 \\
(0.0044)\end{array}$ & $\begin{array}{l}-0.0035 \\
(0.0027)\end{array}$ \\
\hline $\mathrm{S}_{2}$ & $\begin{array}{c}0.037 \\
(0.021) *\end{array}$ & $\begin{array}{l}-0.067 \\
(0.021) * * *\end{array}$ & $\begin{array}{r}0.0039 \\
(0.013) \\
\end{array}$ & $\begin{array}{c}0.051 \\
(0.033) \\
\end{array}$ & $\begin{array}{l}-0.068 \\
(0.0473) \\
\end{array}$ & $\begin{array}{l}-0.0038 \\
(0.029) \\
\end{array}$ \\
\hline $\mathrm{S}_{3}$ & $\begin{array}{l}0.046 \\
(0.021)^{* *}\end{array}$ & $\begin{array}{l}-0.095 \\
(0.0207) * * *\end{array}$ & $\begin{array}{r}0.0017 \\
(0.013)\end{array}$ & $\begin{array}{l}0.085 \\
(0.033)^{* *}\end{array}$ & $\begin{array}{l}-0.1045 \\
(0.0473)^{* *}\end{array}$ & $\begin{array}{l}-0.032 \\
(0.0289)\end{array}$ \\
\hline $\mathrm{CF}$ & $\begin{array}{l}-0.013 \\
(0.017)\end{array}$ & $\begin{array}{l}-0.0154 \\
(0.069)\end{array}$ & $\begin{array}{l}-0.0067 \\
(0.0110)\end{array}$ & $\begin{array}{l}-0.044 \\
(0.027)\end{array}$ & $\begin{array}{l}0.0301 \\
(0.0386)\end{array}$ & $\begin{array}{l}0.0067 \\
(0.0236)\end{array}$ \\
\hline $\mathrm{S}_{2} *$ Trend & $\begin{array}{l}0.005 \\
(0.0019) * * *\end{array}$ & $\begin{array}{c}0.0014 \\
(0.0019)\end{array}$ & $\begin{array}{l}0.0029 \\
(0.0012)^{* *}\end{array}$ & $\begin{array}{c}0.0066 \\
(0.0037)^{*}\end{array}$ & $\begin{array}{c}0.0060 \\
(0.0054)\end{array}$ & $\begin{array}{c}0.0057 \\
(0.0038)\end{array}$ \\
\hline $\mathrm{S}_{3} *$ Trend & $\begin{array}{l}0.007 \\
(0.0019) * * *\end{array}$ & $\begin{array}{c}0.0033 \\
(0.0019) *\end{array}$ & $\begin{array}{l}0.0035 \\
(0.0012)^{* * *}\end{array}$ & $\begin{array}{l}0.0121 \\
(0.0037)^{* * *}\end{array}$ & $\begin{array}{l}0.0170 \\
(0.0054)^{* * * *}\end{array}$ & $\begin{array}{l}0.0140 \\
(0.003)^{* * *}\end{array}$ \\
\hline CF*Trend & $\begin{array}{c}0.0013 \\
(0.0015)\end{array}$ & $\begin{array}{c}-0.0003 \\
(0.0015)\end{array}$ & $\begin{array}{c}0.0008 \\
(0.0009)\end{array}$ & $\begin{array}{l}0.0082 \\
(0.0031)^{* * *}\end{array}$ & $\begin{array}{l}-0.0007 \\
(0.0044)\end{array}$ & $\begin{array}{c}0.0052 \\
(0.003)^{*}\end{array}$ \\
\hline $\mathrm{R}^{2}$ & 0.16 & 0.10 & 0.08 & 0.20 & 0.04 & 0.12 \\
\hline
\end{tabular}

Note: Three asterisks $(* * *)$, two asterisks $(* *)$ and one asterisk $(*)$ represents the significance of the coefficient at $99 \%, 95 \%$ and $90 \%$ levels, respectively. 


\section{References}

Bailey, M., E.J. Bartelsman and J. Haltiwanger. 1996. "Downsizing and Productivity Growth: Myth or Reality," in Sources of Productivity Growth. Edited by D. Mayes. Cambridge: Cambridge University Press. 263-88.

Baldwin, J.R. 1995. The Dynamics of Industrial Competition. Cambridge: Cambridge University Press.

Baldwin, J.R. 1996. "Productivity Growth, Plant Turnover and Restructuring in the Canadian Manufacturing Sector," in Sources of Productivity Growth. Edited by D. Mayes. Cambridge: Cambridge University Press. 245-262.

Baldwin, J.R. 1998. "Were Small Firms the Engines of Growth in the 1980s," Small Business Economics, 10: 349-64.

Baldwin, J.R. and B. Diverty. 1995. "Advanced Technology Use in Manufacturing Establishments," Research Paper No. 85. Analytical Studies Branch. Ottawa: Statistics Canada.

Baldwin, J.R., B. Diverty and D. Sabourin. 1995. Technology Use and Industrial Transformation. Research Paper No. 61. Analytical Studies Branch. Ottawa: Statistics Canada.

Baldwin, J.R. and P.K. Gorecki. 1990. Structural Change and the Adjustment Process: Perspectives on Establishment Growth and Worker Turnover. Ottawa: Economic Council of Canada.

Baldwin, J.R. and P.K. Gorecki. 1991. "Entry, Exit and Productivity Growth," in P. Geroski and J. Schwalbach (eds.) Entry and Market Contestability: An International Comparison, (Oxford: Basil Blackwell). 244-56

Baldwin, J.R., T. Gray and J. Johnson. 1996a. " Technology-Induced Wage Premia in Canadian Manufacturing Plants During the 1980s," Research Paper No. 92. Analytical Studies Branch. Ottawa: Statistics Canada.

Baldwin, J.R., T. Gray and J. Johnson. 1996b. "Advanced Technology Use and Manufacturing in Canadian Manufacturing," Canadian Business Economics 5: 51-70.

Baldwin, J.R. and J. Johnson. 1999. "Innovation and Entry”. In Are Small Firms Important? Their Role and Impact. Edited by Z. Acs. Kluwer.

Baldwin, J.R. and G. Picot. 1995. "Employment Generation by Small Producers in the Canadian Manufacturing Sector," Small Business Economics 7: 317-31.

Baldwin, J.R. and D. Sabourin. 1995. Technology Adoption in Canadian Manufacturing. Catalogue 88-512-XPE. Ottawa: Statistics Canada. 
Baldwin, J.R. and M. Rafiquzzaman. 1994. Structural Change in the Canadian Manufacturing Sector: 1970-1990, Research Paper No. 61. Analytical Studies Branch, Ottawa: Statistics Canada.

Baldwin, J.R. and M. Rafiquzzaman. 1995. "Selection versus Evolutionary Adaptation: Learning and Post-Entry Performance," International Journal of Industrial Organization: 13: 501-522.

Baldwin, J.R. and M. Rafiquzzaman. 1998. "The Effect of Technology and Trade on Wage Differentials Between NonProduction and Production Workers in Canadian Manufacturing," in Innovation, Industry Evolution and Employment. Edited by D. Audretsch and R. Thurik. Cambridge: Cambridge University Press.

Baldwin, J.R., E. Rama and D. Sabourin. 1999. Growth of Advanced Technology Use in Canadian Manufacturing during the 1990s. Research Paper No. 105. Analytical Studies Branch. Ottawa: Statistics Canada.

Caves, R.E. 1982. Multinational Enterprise and Economic Analysis. Cambridge: Cambridge University Press.

Dunning, J.H. 1993. Multinational Enterprises and the Global Economy. New York: AddisonWesley.

Globerman, S., J.C. Ries and I. Vertinsky. 1994. "The economic performance of foreign affiliates in Canada," Canadian Journal of Economics 27:143-156.

Hamermesh, D.S. 1993. Labor Demand. Princeton, N.J.: Princeton University Press.

Heckman, James J., 1979, "Sample Selection Bias as a Specification Error," Econometrica, Vol. 47, No. 1, pp. 153-161.

Picot, G., Z. Lin and W. Pyper. 1997. Permanent Layoffs in Canada. Overview and Longitudinal Analysis. Research Paper No. 103. Analytical Studies Branch, Ottawa: Statistics Canada.

Greene H. William. 1997. Econometric Analysis, 3rd edition, New Jersey: Prentice Hall.

Statistics Canada, The Ownership, Control and the Country of Control of Corporations. Unpublished manuscript, 1987. 